\title{
Relational Mate Value: Consensus and Uniqueness in Romantic Evaluations
}

\author{
Paul W. Eastwick and Lucy L. Hunt \\ University of Texas at Austin
}

\begin{abstract}
Classic evolutionary and social exchange perspectives suggest that some people have more mate value than others because they possess desirable traits (e.g., attractiveness, status) that are intrinsic to the individual. This article broadens mate value in 2 ways to incorporate relational perspectives. First, close relationships research suggests an alternative measure of mate value: whether someone can provide a high quality relationship. Second, person perception research suggests that both trait-based and relationship quality measures of mate value should contain a mixture of target variance (i.e., consensus about targets, the classic conceptualization) and relationship variance (i.e., unique ratings of targets). In Study 1 , participants described their personal conceptions of mate value and revealed themes consistent with classic and relational approaches. Study 2 used a social relations model blocked design to assess target and relationship variances in participants' romantic evaluations of opposite-sex classmates at the beginning and end of the semester. In Study 3, a one-with-many design documented target and relationship variances among long-term opposite-sex acquaintances. Results generally revealed more relationship variance than target variance; participants' romantic evaluations were more likely to be unique to a particular person rather than consensual. Furthermore, the relative dominance of relationship to target variance was stronger for relational measures of mate value (i.e., relationship quality projections) than classic trait-based measures (i.e., attractiveness, resources). Finally, consensus decreased as participants got to know one another better, and long-term acquaintances in Study 3 revealed enormous amounts of relationship variance. Implications for the evolutionary, close relationships, and personperception literatures are discussed.
\end{abstract}

Keywords: mate value, relationship quality, social relations model, attraction, evolutionary psychology

The notion that people differ in their mate value seems obviously true. After all, some people are more skilled, more attractive, and more intelligent than others, and natural selection endowed humans with the preference for such traits in romantic partners (Buss \& Barnes, 1986; Fletcher, Simpson, Thomas, \& Giles, 1999; Kurzban \& Leary, 2001). These desirable traits are like commodities in a mating market, and a person's consensually agreed-upon mate value is the sum of these traits (Kirsner, Figueredo, \& Jacobs, 2003). Thus, people achieve their own best possible mating outcomes by accurately acknowledging their desirable and undesirable qualities and pursuing mates who match that level of desir-

This article was published Online First March 10, 2014.

Paul W. Eastwick and Lucy L. Hunt, Department of Human Development and Family Sciences, University of Texas at Austin.

This article was facilitated by National Science Foundation Grant BCS1243323 awarded to Paul W. Eastwick. We are grateful to David Kenny for his considerable assistance in preparing the SAS code for the analyses in Studies 2 and 3, and we thank Lisa Neff and Eli Finkel for their helpful comments on an earlier draft of this article. Also, we thank our hardworking research assistants: Natalie Bodak, Demetrias Byrd, Samantha Caplan, Daniel Cepeda, Gretchen Geltemeyer, Abigail Godinez, Courtney Umstattd, and Heidi Wendenburg.

Correspondence concerning this article should be addressed to Paul W. Eastwick, Department of Human Development and Family Sciences, University of Texas at Austin, 108 East Dean Keeton Street, Stop A2702, Austin, TX 78712. E-mail: eastwick@austin.utexas.edu ability (Todd \& Miller, 1999). This received wisdom from evolutionary and social exchange theories rests at the heart of contemporary examinations of mate value (e.g., Kavanagh, Robins, \& Ellis, 2010; Penke, Todd, Lenton, \& Fasolo, 2007) and even extends to popular classroom demonstrations of the romantic pairing process (Ellis \& Kelley, 1999). In short, people who have it all can get it all in a mate, and people at the lower end of the mate value spectrum settle for one another, "crestfallen" about their mating fortunes (Fletcher, Simpson, Campbell, \& Overall, 2013, p. 126).

Yet before completely embracing this account, consider another set of social psychological maxims: Information about the social world must be filtered and interpreted by human minds (Lewin, 1935, 1936; Ross, 1987; Ross \& Nisbett, 1991). That is, people have their own subjective construal of the world, and this subjectivity likely applies to the way that we perceive the assets and shortcomings of other people (Kenny, 2004). Thus, even if people do differ in the extent to which they possess desirable qualities, this objective reality may not reflect how people subjectively experience the mating process.

Drawing from these latter perspectives, we present in this article a novel, relational approach to the study of mate value. Although the classic blend of social exchange and evolutionary perspectives on this topic has been valuable, we suggest that this depiction of mate value is incomplete and fails to capture important elements of the way that people experience mate value as they consider their real-life romantic options. Instead, our new conceptualization of 
mate value derives two insights from the literatures on close relationships (Berscheid \& Reis, 1998) and person perception (Kenny, 1994, 2004). First, the close relationships literature suggests the utility of assessing not only desirable traits but also dyad-specific projections of relationship quality (e.g., satisfaction) as a proxy for mate value. Second, the person perception literature suggests that the tendency for mate value judgments to be unique to a particular dyad (i.e., relationship variance) could be stronger than the tendency for those judgments to coalesce around another person's consensual mate value "reality" (i.e., target variance). In Study 1, we find that participants' lay conceptions of mate value are consistent with these relational themes, and Studies 2 and 3 reveal that most judgments of mate value are more relational than consensual, especially as people get to know each other better over time. These results hint at the possibility that, despite the unbalanced distribution of desirable traits in the population, mating pursuits take place on a more-or-less even playing field in which most people have a strong chance of being satisfied with their romantic outcomes (Eastwick \& Buck, in press).

\section{The Classic Perspective on Mate Value}

The term mate value was originally applied to humans by Symons (1987), who reviewed evolutionary theory suggesting that (a) physical attractiveness and youth should be particularly important determinants of women's mate value and (b) status and prowess should be particularly important determinants of men's mate value. Subsequent treatments of this topic (e.g., Kenrick, Groth, Trost, \& Sadalla, 1993) broadened mate value to incorporate social exchange perspectives on mating (Cameron, Oskamp, \& Sparks, 1977) as well as other consensually valued traits (e.g., intelligence, emotional stability).

Today the concept of mate value is ubiquitous in the literature on human mate selection. Typically, mate value is defined as the genetic or material contributions that a person can offer in a mating relationship that ultimately contribute to an offspring's reproductive success (Brase \& Guy, 2004; Kirsner et al., 2003; Waynforth, 2001). For example, a person might have traits indicating favorable genetic endowments (e.g., physical attractiveness, low fluctuating asymmetry) that bode well for an offspring's future health and survival. Alternatively, a person might have skills (e.g., hunting prowess) and attributes (e.g., dominance, high status) that would make that person effective at providing for his or her offspring. Especially relevant to the present article is that this definition contains the (sometimes implicit) assumption that these traits are inherent properties of the target. In other words, at a given moment, each person has an objective mate value that is "intrinsic to an individual" (Fisher, Cox, Bennett, \& Gavric, 2008, p. 157) and assessable by others with some degree of consensus.

Given the predominant perspective that mate value is trait-like, nearly all assessments of mate value consist of the self-reporting of desirable traits (Brase \& Guy, 2004; Campbell, Simpson, Kashy, \& Fletcher, 2001; Campbell \& Wilbur, 2009; Ellis, Simpson, \& Campbell, 2002; Figueredo, Sefcek, \& Jones, 2006; Fisher et al., 2008; Kenrick et al., 1993; Kirsner et al., 2003; Overall, Fletcher, \& Simpson, 2006; Penke \& Denissen, 2008; Regan, 1998a, 1998b; Todd, Penke, Fasolo, \& Lenton, 2007), although some operationalizations of mate value consist of participants' estimates of their own romantic popularity (Apicella \& Marlowe, 2007; Back,
Penke, Schmukle, \& Asendorpf, 2011; Eastwick \& Finkel, 2008; Gutierres, Kenrick, \& Partch, 1999; Landolt, Lalumière, \& Quinsey, 1995). Consistent with both assessment strategies, mate value has often been likened to a domain-specific component of selfesteem-a sociometer that is specific to romantic relationships and reflects how well people believe that they are able to attract members of the opposite sex (Kirkpatrick \& Ellis, 2001; Kavanagh et al., 2010).

Several empirical studies support the predictive utility of mate value self-assessments. The most consistent finding in the mate value literature is that people with higher self-reported mate value (i.e., higher self-esteem in the mating domain) report higher standards for the qualities that they desire in romantic partners (Campbell et al., 2001; Kenrick et al., 1993; Kirsner et al., 2003; Regan, 1998b). This finding is consistent with both the social exchange and evolutionary predictions that people should pursue the best partner that they can realistically obtain (Kirkpatrick \& Ellis, 2001; Todd \& Miller, 1999) — that is, people with wonderful traits should expect that their partners will have wonderful traits. Researchers have also examined how mate value affects people's pursuit of real-life romantic partners in speed-dating contexts, finding that people who believe they have high mate value behave in appealing ways that foster their own popularity and/or selectivity (Back, Penke, Schmukle, Sachse, et al., 2011; Todd et al., 2007). In summary, the classic perspective on mate value suggests a sequence such that people (a) possess an intrinsic mate value that can be assessed by prospective or current mates, (b) learn their mate value via repeated experiences with romantic rejection and acceptance, and (c) evaluate and pursue mates differently depending on how their mate value self-assessments compare with their assessments of others on the dating market.

The extant data reviewed above provide support for Steps b and c, but what about Step a-the core definitional assumption underlying the concept of mate value? In fact, there is evidence for this idea in initial impression contexts, as opposite-sex raters achieve consensus (i.e., ratings show convergence across targets) about who is attractive and desirable after initial encounters (e.g., Asendorpf, Penke, \& Back, 2011; Marcus \& Miller, 2003). In other words, in the moment that initial impressions are formed, there is some quality "intrinsic to an individual" that differentiates desirable from undesirable partners.

But does the evidence for consensus about mating desirability persist beyond initial impression contexts? This question is critical, as humans' mating relationships involve much more than a single impression and sexual act. Close committed romantic relationships can last for years, and even outside established relationship contexts, sexual encounters between two individuals who have just met may be somewhat rare. Illustrating this latter point, one study that tracked single men's attraction experiences in their daily lives found that men had known the women they were pursuing for over a year on average (Eastwick, Morgan, et al., 2013; for similar time frames prior to forming a "friends with benefits" relationship, see Bisson \& Levine, 2009). Also, a representative sample of adolescents reporting on their most recent sexual experiences revealed that only $6 \%$ of dyads were unacquainted prior to becoming romantically involved; most couples knew each other beforehand as friends (41\%) or acquaintances (53\%; Kaestle \& Halpern, 2005; for similar values, see Ingham, Woodcock, \& Stenner, 1991; Manning, Giordano, \& Longmore, 2006; Traeen, Lewin, \& Sun- 
det, 1992). Indeed, models in the close relationships literature posit that opposite-sex individuals frequently get to know one another over long stretches of time (Afifi \& Faulkner, 2000; Baxter \& Bullis, 1986; Bullis, Clark, \& Sline, 1993; Huston, Surra, Fitzgerald, \& Cate, 1981; Knapp, 1984), and the majority of romantic encounters spring from these initially nonromantic relationships. Do people also experience greater or lesser success in these contexts because of an internal, trait-like mate value that is intrinsic to an individual? As the ensuing review suggests, the mate value consensus that emerges in initial impression settings could actually turn out to be somewhat ephemeral.

\section{A Relational Approach to Studying Mate Value}

Our relational perspective on mate value differs from the classic perspective in two respects. First, we draw from the close relationships literature to suggest that in addition to desirable traits (e.g., physical attractiveness, status, popularity), judgments about relationship quality might also be conceptualized as measures of mate value. Second, we draw from the person perception literature to challenge the assumption that any measure of mate valuewhether on trait-like constructs or relationship quality constructs-is necessarily a quality of the target. Given that two people can uniquely inspire the expression of traits and the experience of positive affect in each other, much of the variance in mate value judgments may be a function of the dyad.

\section{Relationship Quality Projections as Measures of Mate Value}

There is a strong evolutionary rationale behind humans' tendency to form long-term, pair-bonded mating relationships. According to attachment theory, natural selection forged attachment bonds between adult mating partners to increase the likelihood that they (especially the father) would invest in the extremely helpless offspring of the bonded partnership (Eastwick, 2009; Fraley \& Shaver, 2000; Hazan \& Diamond, 2000; L. C. Miller \& Fishkin, 1997; Stewart-Williams \& Thomas, 2013; Zeifman \& Hazan, 2008). Investment partially consists of concrete resources, as acknowledged by the evolutionary models discussed above, but it also consists of investments of time-time in which the direct and indirect transmission of a parent's knowledge can build an offspring's skills and social competence (Eastwick, 2013; Hewlett, 2000; Kaplan, Lancaster, Johnson, \& Bock, 1995; Katz \& Konner, 1981; Nielsen \& Tomaselli, 2010). Thus, the pair bond evolved to maximize the likelihood that humans would raise healthy, thriving offspring who survive to reproduce themselves (Geary, 2000; Hurtado \& Hill, 1992; Winking, 2006).

A massive literature on adult close relationships is dedicated to studying the processes underlying the formation and maintenance of such pair-bonded relationships (Bradbury \& Karney, 2010; Fletcher et al., 2013; R. S. Miller, 2012). This literature has coalesced around several interrelated assessments of relationship quality, such as satisfaction, commitment, and love (Fletcher, Simpson, \& Thomas, 2000). Typically, research in the close relationships tradition uses these affectively laden measures as indicators of effective relationship functioning and identifies the factors that cause these constructs to wax and wane. Therefore, if there is an analog of mate value in this literature, presumably it would be reflected by these measures of relationship quality. In other words, just as someone with high mate value in initial impression settings would inspire romantic interest and sexual desire in others, someone with high mate value in the relationships domain would inspire relationship satisfaction and love in others.

Unlike the classic mate value trait assessments described above, relationship quality items typically bring the dyad into focus (e.g., "Our relationship is better than others' romantic relationships"; Rusbult, Martz, \& Agnew, 1998). Yet such judgments might or might not be dyadic at their core: Consistent with the idea that mate value describes a quality intrinsic to the individual, it is possible that some people generally tend to be better than others at providing a partner with a satisfying close relationship, regardless of who that partner might be.

One relevant literature has examined how individual differences such as neuroticism (Donnellan, Conger, \& Bryant, 2004), attachment style (Campbell, Simpson, Boldry, \& Kashy, 2005), and self-esteem (Murray, Holmes, \& Griffin, 2000) affect relationship functioning. Such self-evaluations are undoubtedly associated with the strategies that people use to manage and maintain their existing relationships (McNulty, 2013). Yet the most reliable findings in this literature are rater (i.e., actor) effects, that is, how an individual's personality affects his or her own experience and behavior within a relationship. The core definitional assumption about mate value refers instead to target (i.e., partner) effects: Some individuals are better than others as mates, and this intrinsic mate value should be reflected in a partner's experiences with and evaluations of the individual. Such partner effects do occasionally emerge (e.g., the Donnellan et al., Campbell et al., and Murray et al. studies cited above), but in the close relationships literature, these effects tend to be small on average. For example, a recent study examining two large representative samples found that although participants' relationship satisfaction was higher to the extent that their partner was emotionally stable, agreeable, and conscientious, these variables jointly accounted for only about $2 \%$ of the variance in relationship satisfaction (Dyrenforth, Kashy, Donnellan, \& Lucas, 2010); variance due to actor effects was 3 times larger.

Personality predictors aside, the most direct test of the idea that some people are better than others at providing a satisfying relationship would examine the level of consensus in romantic partners' reports of satisfaction, love, and commitment regarding the same person. As elaborated below, if an internal quality differentiates partners who have high versus low relational mate value, then participants should achieve substantial consensus when rating the extent to which a given partner is able to provide a satisfying relationship. Of course, there is a simple reason why no study has calculated such consensus for relationship quality constructs: At a given moment in time, few people have more than one romantic partner (cf. Conley, Ziegler, Moors, Matsick, \& Valentine, 2013). Thus, one goal of the current project was to overcome this hurdle by developing a way of assessing participants' estimates of projected relationship quality regarding opposite-sex others with whom they did not actually have a romantic relationship.

\section{Are Mate Value Judgments Inherent to the Target or the Dyad?}

As just noted, one of the best ways of identifying whether there is indeed an internal, trait-like quality that is intrinsic to an indi- 
vidual is to see whether multiple raters achieve consensus about who does and does not possess the quality. This insight is a key component of the social relations model, which is a model that parses dyadic data into independent sources of statistical variance (Back \& Kenny, 2010; Kenny, 1994; Kenny, Kashy, \& Cook, 2006; Kenny \& La Voie, 1984). When multiple individuals rate one another on a construct, the social relations model separates those ratings into four components. The first is perceiver (i.e., actor) variance, also called assimilation, which refers to the extent to which perceivers differ in the extent to which they generally rate targets. A situation where a perceiver Andy likes targets on average and another perceiver Betty dislikes targets on average indicates high perceiver variance. The second is target (i.e., partner) variance, also called consensus, which refers to the extent to which targets differ in how they are generally rated by perceivers. A situation where a target Cassandra is liked by perceivers on average and another target Dane is disliked by perceivers on average indicates high target variance. The third is relationship variance, also called uniqueness, which refers to the extent to which perceivers differ in their ratings of specific targets above and beyond actor and target variance. A situation where Betty (who dislikes targets on average) reports strong liking for Dane (who is disliked by perceivers on average) indicates high relationship variance. The fourth is error, which refers to variations in ratings due to chance responding.

Target variance is a critical component of the classic approach to mate value; if prospective or current mates can assess a target's intrinsic mate value, then consensus will emerge. Alternatively, relationship variance-the idea that people see one another as uniquely desirable or undesirable-provides a new way of conceptualizing mate value that could in principle apply to both trait and relationship quality constructs.

Although this idea has not been presented in formal statistical terms in prior work, the close relationships literature alludes to the importance of uniqueness. For example, compatibility is a term describing two people who work or fit especially well together (Ickes, 1985), and participants' holistic judgments of compatibility (and similarity, a specific subtype of compatibility) correlate highly with positive relational outcomes (Berscheid, 1985; Sprecher, 2011; Tidwell, Eastwick, \& Finkel, 2013). In addition, Murray and Holmes (2009) noted that being of unique value to another person should foster a trusting and mutually responsive relationship: If a woman is viewed by her partner as irreplaceable, then her partner should offer costly help in her time of need. Consistent with the ideal standards model (Fletcher \& Simpson, 2000; Simpson, Fletcher, \& Campbell, 2001), people differ in their ideal partner preferences for certain traits, and people tend to be happier in their relationships to the extent that their romantic partner's traits matches this idiosyncratic pattern of ideals (Eastwick, Luchies, Finkel, \& Hunt, 2013). Finally, in reflecting on various methods that people have used to maintain and improve their marriages, Glenn (2002, p. 48) hypothesized that "the most stable and successful marriages are likely to be those in which the spouses are substantially more desirable to one another than they are to most other people." Yet studies on romantic relationships have not examined this idea formally because they have not taken advantage of social relations model designs.

Nevertheless, some prior studies hint at how the social relations model can enhance our understanding of mate value. In both romantic and platonic initial impression settings, studies reveal moderate-to-strong target variance (i.e., 15\%-30\%) for desirable traits (e.g., attractiveness, intelligence, responsiveness) as well as likability (Back, Schmukle, \& Egloff, 2011; Eastwick \& Finkel, 2007; Eastwick, Finkel, Mochon, \& Ariely, 2007; Kenny, 1994, 2010; Park, Kraus, \& Ryan, 1997). These findings largely support the classic conception of mate value: People vary in the extent to which they possess desirable traits and are themselves likable, and these mate value differences are reliably perceived by others in initial interactions. However, these same studies also revealed a strong amount of relationship variance (i.e., 30\% and higher); thus, even when forming initial impressions, the importance of uniqueness may rival the importance of consensus.

Furthermore, consensus does not typically increase as raters get to know each other over time (Kenny, 1994, 2004; Kenny, Albright, Malloy, \& Kashy, 1994; but see Funder \& Colvin, 1988). In fact, consensus may decrease over time as raters start to base their judgments on their own idiosyncratic impressions of a target's specific behaviors. Consistent with this possibility, target variance is quite low when people rate well-known others such as friends (2\%; Lakey, McCabe, Fisicaro, \& Drew, 1996), family members ( $\leq 6 \%$; Branje, van Aken, \& van Lieshout, 2002), and mentors ( $\leq 8 \%$; Giblin \& Lakey, 2010) on affect-laden variables such as perceived supportiveness; in contrast, relationship variance estimates in these studies were considerably higher $(\sim 40 \%)$. Therefore, there are reasons to suspect that relationship variance will dwarf target variance in a situation where opposite-sex individuals get to know one another gradually and rate each other on romantically relevant traits and constructs, like those used in both the mate value and close relationships literatures.

\section{The Current Research}

To examine the soundness of our relational approach to mate value, we first conducted a study in which we asked participants to describe what the term mate value meant to them. We coded participants' responses for the appearance of (a) attractiveness, financial resources, popularity, and related desirable traits; (b) relationship quality constructs such as satisfaction and commitment; and (c) the social relations model concept of compatibility. With this study, we wanted to examine empirically the extent to which participants' lay understanding of mate value dovetailed with both the classic approach to mate value (i.e., desirable traits) and our relational approach (i.e., relationship quality, compatibility).

Next, we report the results of two social relations model studies that allowed us to separate participants' romantic evaluations of opposite-sex individuals into perceiver, target, and relationship variance. We performed variance partitioning on participants' ratings of classic mate value constructs as well as a new relational measure of mate value that we derived from Study 1 and from commonly used relationship quality constructs (Fletcher et al., 2000; Rusbult et al., 1998). In Study 2, we collected opposite-sex ratings of these various constructs at the beginning and the end of the semester among individuals taking a small class together. Study 3 used a one-with-many design in which participants and opposite-sex long-term acquaintances completed informant reports about each other (Vazire, 2006). Our primary hypothesis across these two studies was that participants' ratings would generally 
reveal more relationship variance than target variance. We anticipated that this pattern should emerge for classic measures of mate value (e.g., attractiveness, status, popularity) as well as our new relational measure, but the relative dominance of relationship variance to target variance may be especially strong for our new relational measure of mate value that assesses projected relationship quality.

\section{Study 1}

This study was inspired by the work of Fletcher et al. (1999), who asked participants to describe what traits were particularly important to them in an ideal romantic partner. Although scholars had conducted research on ideal partner preferences since the 1940s, all prior questionnaires had derived the trait items from the intuition of the initial survey creators (Christensen, 1947; Hill, 1945); thus, the Fletcher et al. study added valuable external validity to the study of ideal partner preferences (for a review, see Eastwick, Luchies, et al., 2013). In Study 1, we aimed for a similar goal regarding the concept of mate value by coding participants' open-ended reports about what the term mate value meant to them. We hypothesized that participants would indeed mention traits that are common in the mate value literature (e.g., attractiveness, intelligence, financial resources) when describing their own personal concept of mate value. Furthermore, if participants' lay understanding of mate value is similar to the relational approach outlined above, they should mention relationship quality constructs and compatibility as well-perhaps even more frequently than they mention traits. We also drew from the insights of the Study 1 participants to inform the development of a relational mate value measure for use in Studies 2 and 3.

\section{Method}

Participants. Participants were 88 undergraduate students (39 men, 49 women) who took part in the study to achieve partial fulfillment of a course requirement. The age and ethnicity of these participants were not recorded, but they came from a population of Introductory Psychology students who were 18.9 years old $(S D=$ 1.2) on average and who were $4 \%$ African American/Black, $5 \%$ Asian/Pacific Islander, 15\% Hispanic, 73\% White/Caucasian, and $3 \%$ other or mixed race.

Procedure. Participants arrived at the laboratory and read the following instructions on a computer:

\footnotetext{
We are working to better understand how people think about the concept of "mate value." Please take 5 minutes to explain what "mate value" means to you. For example, what does it mean to say that someone is a valuable mate for you? What does it mean to say that you are a valuable mate for someone else?
}

Participants typed their responses into the computer. After $5 \mathrm{~min}$ had elapsed, the computer program automatically initiated another questionnaire that is not relevant to the current investigation.

Materials. We coded the essay responses of the 88 participants for the presence or absence of several features central to the concept of mate value (see Table 1). Two research assistants coded the essays; free-marginal kappas ranged from .82 to 1.00 (average $\kappa=.97$ ). Disagreements were resolved by the second author.

A number of the features in the coding rubric derived theoretically from prior work on mate value as well as from the relational
Table 1

Features Mentioned in Participants' Mate Value Essays, Study 1

\begin{tabular}{|c|c|}
\hline Feature & Percent mentioned \\
\hline \multicolumn{2}{|l|}{ Vitality/attractiveness } \\
\hline Attractive & 29.5 \\
\hline Outgoing & 3.4 \\
\hline Good lover & 1.1 \\
\hline Nice body & 1.1 \\
\hline Sexy & 0.0 \\
\hline Adventurous & 0.0 \\
\hline Total & 31.8 \\
\hline \multicolumn{2}{|l|}{ Status/resources } \\
\hline Intelligent & 11.4 \\
\hline Financially secure & 5.7 \\
\hline Dresses well & 2.3 \\
\hline Good job & 1.1 \\
\hline Nice house or apartment & 0.0 \\
\hline Successful & 0.0 \\
\hline Total & 19.3 \\
\hline Popularity & 0.0 \\
\hline \multicolumn{2}{|l|}{ Relationship quality components } \\
\hline Commitment & 36.4 \\
\hline Satisfaction & 21.6 \\
\hline Intimacy & 19.3 \\
\hline Trust & 15.9 \\
\hline Love & 9.1 \\
\hline Passion & 1.1 \\
\hline Total & 64.8 \\
\hline \multicolumn{2}{|l|}{ Social relations model concepts } \\
\hline Compatibility & 45.5 \\
\hline Similarity & 8.0 \\
\hline Total & 48.9 \\
\hline \multicolumn{2}{|l|}{ Other common traits $(>10 \%)$} \\
\hline Caring & 21.6 \\
\hline Understanding & 15.9 \\
\hline Supportive & 11.4 \\
\hline Humorous/funny & 11.4 \\
\hline \multicolumn{2}{|l|}{ Other common concepts $(>10 \%)$} \\
\hline Improving one's life or self & 27.3 \\
\hline Having/sharing values or morals & 19.3 \\
\hline Companionship & 15.9 \\
\hline Respect & 14.8 \\
\hline Parenting and family & 14.8 \\
\hline
\end{tabular}

Note. "Total" indicates the percentage of essays mentioning at least one of the features in the category.

mate value perspective described above. Specifically, we coded whether each essay mentioned vitality/attractiveness traits and status/resources traits (Fletcher et al., 1999; see Table 1). These constructs are central to the prior evolutionary and social exchange literatures on mate value, and these self-report items have been conceptualized as assessments of mate value in prior research (e.g., Boyes \& Fletcher, 2007; Campbell \& Wilbur, 2009; Fletcher, Tither, O'Loughlin, Friesen, \& Overall, 2004; Overall et al., 2006). We also coded for popularity, which is a major theme in the widely used Landolt et al. (1995) measure of mate value. Throughout this article, we refer to these three measures (vitality/attractiveness, status/resources, and popularity) as the classic mate value measures.

We also coded for features relevant to our two novel relational insights about mate value. Specifically, we coded whether each essay mentioned Fletcher et al.'s (2000) six relationship quality components, which are satisfaction, commitment, intimacy, trust, passion, and love. Also, we coded whether each essay mentioned 
the social relations model concept of compatibility as well as similarity, which is a specific (well-studied) form of compatibility.

The coding rubric was further enhanced by a bottom-up, datadriven approach. The second author read the essays and identified additional common traits and themes that were not captured by the classic mate value or relational mate value theoretical approaches (e.g., companionship, respect). Those that that the coders identified in more than $10 \%$ of the essays are included as well in Table 1.

\section{Results}

As evident in Table 1, participants' lay understanding of mate value was consistent with both the classic trait-based perspectives and our relational perspective. With respect to the classic mate value approaches, approximately one third of the essays mentioned a trait relevant to the vitality/attractiveness construct, and approximately $20 \%$ of the essays mentioned a trait relevant to the status/ resources construct. However, none of the participants cited popularity as an important component of mate value; that is, no one mentioned that a valuable mate was someone who was popular with members of the opposite sex or popular with others in general.

Participants' essay descriptions were also consistent with our relational approach to mate value. Nearly two thirds of participants mentioned one of the six relationship quality components (Fletcher et al., 2000), and approximately half the participants mentioned compatibility. Chi-square tests comparing the total percentages for the three classic mate value measures, the relationship quality components, and the social relations model concepts revealed that all differences were at least marginally significant. That is, relationship quality was mentioned more often than social relations model concepts, $\chi^{2}(1)=4.54, p=.033$, which were mentioned more often than vitality/attractiveness traits, $\chi^{2}(1)=5.31, p=$ .021 , which were mentioned more often than status/resources traits, $\chi^{2}(1)=3.61, p=.057$, which were mentioned more often than popularity, $\chi^{2}(1)=18.82, p<.001$. Two sample essays are included in Appendix A; the first exemplifies the classic approach to mate value (albeit with some relational elements), and the second exemplifies the relational approach.

Several additional traits and concepts appeared in $10 \%$ or more of the essays. A few of these traits were consistent with the Fletcher et al. (1999) construct warmth/trustworthiness-namely caring, understanding, and supportive. Also, approximately $10 \%$ of participants associated mate value with a good (or compatible) sense of humor (Wilbur \& Campbell, 2011). Furthermore, several commonly mentioned concepts were consistent with the relational approach but not captured by the Fletcher et al. (2000) relationship quality components. Specifically, participants often described a person with high mate value as someone who improved their life, shared their values, provided companionship, respected them, and would fit in with their existing family and/or wanted to start their own family.

\section{Discussion}

Despite the large corpus of research on mate value, the current study is the first to examine participants' own beliefs about the concept. We used a method similar to the one used by Fletcher et al. (1999) in their initial examination of participants' open-ended responses regarding ideal partner preferences. The essays in the current study revealed themes in common with both the classic and relational approaches to mate value. In keeping with classic evolutionary approaches to the study of mate value (Symons, 1987; Waynforth, 2001), participants mentioned both attractiveness (32\%) and resource-linked traits (19\%). In addition, the relational approach received support in that participants regularly mentioned relationship quality measures such as commitment, satisfaction, and intimacy $(65 \%)$; they also mentioned the social-relationsmodel-derived idea that a high value mate is a compatible mate (49\%). In general, participants tended to mention the relational mate value concepts more often than they mentioned the classic mate value concepts. Finally, no participant mentioned popularity as an important determinant of mate value. Nevertheless, we continue to examine popularity-based measures of mate value in Studies 2 and 3 given the prominence of such measures in prior research (Landolt et al., 1995).

Additional noteworthy elements emerged in the essays. We anticipated that participants would mention relationship quality constructs (Fletcher et al., 2000) — and they did — but participants also mentioned related constructs such as values, parenting, family, respect, and companionship that were not well captured by the relationship quality components. We incorporated these concepts into our relational measure of mate value in Studies 2 and 3. Also, many participants mentioned traits from the Fletcher et al. (1999) warmth/trustworthiness construct (e.g., understanding, supportive). Because this construct is high in relationship relevance (Kwang \& Swann, 2010) and often emerges as an important predictor of close relationships interpersonal processes (e.g., Murray, Holmes, \& Griffin, 1996a, 1996b), it could perhaps be classified as a relational measure of mate value. However, these traits have occasionally appeared in classic measures of mate value (e.g., Kenrick et al., 1993; Kirsner et al., 2003), and their inclusion has been justified by a blend of evolutionary and economic perspectives that incorporate any traits that make a person a good social exchange partner in general. Given that warmth/trustworthiness traits could derive from both classic and relational perspectives on mate value, we could not justify classifying this construct as exclusively belonging to either category of measure. Nevertheless, we examined it in Studies 2 and 3 for exploratory purposes.

\section{Study 2}

Study 2 used a social relations model approach to illuminate how opposite-sex individuals view one another with respect to various measures of mate value. These individuals became acquainted over the course of a semester as they attended a small class that required active participation. On two occasions (i.e., at the beginning and end of the semester), we assessed participants' ratings of one another on vitality/attractiveness and status/resources traits as well as the Landolt et al. (1995) popularity measure of mate value. If these measures assess qualities intrinsic to individuals that differentiate high from low mate value participants, then a meaningful amount of target variance (i.e., $10 \%$ or more; Kenny et al., 2006) should emerge on these measures; that is, raters should agree on who does and does not possess them. Nevertheless, given prior social relations model studies on affectively laden measures (Back, Schmukle, \& Egloff, 2011; Kenny, 1994; Lakey et al., 1996), we also hypothesized that these ratings 
would exhibit more relationship variance than target variance (Hypothesis 1).

One purpose of Study 1 was to inform our development of a relational mate value measure for Studies 2 and 3. Therefore, for Study 2, we created a set of 14 items that assessed these various relational components of mate value; just as with the classic measures, participants completed these relational items at the beginning and end of the semester. Of course, our participants were classmates, not romantic partners, so we had to administer the measures in such a way that participants could complete them regarding multiple acquaintances. To accomplish this goal, the items were phrased much like a typical relationship quality item (e.g., "Our relationship does a good job of fulfilling my needs for intimacy, companionship, etc."; Rusbult et al., 1998), and we simply asked participants to complete these items as if they were in a romantic relationship with the target. This procedure allowed us to collect bona fide social relations model "block" data on judgments of relationship quality - a feat that otherwise would be impossible given how rarely people possess multiple romantic partners simultaneously. For these relational mate value items, we again hypothesized that relationship variance would be greater than target variance (Hypothesis 1), and we also hypothesized that the relative dominance of relationship to target variance would be stronger for our new relational measure than for the classic measures of mate value (Hypothesis 2).

Finally, we examined how target and relationship variance for all constructs shifted over the course of the semester. These analyses were somewhat exploratory given that no prior research has examined changes over time in social relations model variances of affectively laden measures. Yet if the classic perspective on mate value is relevant primarily to initial impression settings, and if the relational perspective becomes especially important as people spend more time together, then we might observe changes in amount of consensus (i.e., the classic perspective) and/or uniqueness (i.e., the relational perspective) over time. Specifically, target variance could decrease and/or relationship variance could increase between the beginning and the end of the semester (Hypothesis 3).

\section{Method}

Participants. Participants were 129 individuals (28 men, 101 women) who earned extra credit for a class. ${ }^{1}$ Participants were 19.0 years old $(S D=1.5)$ on average; $5 \%$ of the sample identified as African American/Black, $25 \%$ as Asian/Pacific Islander, $31 \%$ as Hispanic, $1 \%$ as Native American, and $38 \%$ as White/Caucasian. At the start of the semester, $34 \%$ reported that they were involved in a romantic relationship.

As part of a large lecture class, the students attended one of nine small group sections (16 or 17 students) once a week for $1 \mathrm{hr}$. Students attended the same section each week, and the grading rubric required that they participate in discussions. These 129 students comprised $91 \%$ of the potentially usable participants (142) from these nine sections: The 13 who did not participate consisted of one student who did not provide consent, five students who were absent the day the experimenter attended the class, five students who consented to participate in the study but did not complete either the Time 1 or Time 2 questionnaire, and two students who provided only partial (i.e., less than 50\%) data.
Participants rated between two and 15 opposite-sex partners depending on group size and composition $(M=4.75$ partner reports at Time 1 and 4.67 at Time 2).

Procedure. Experimenters attended each small group section during the second week of class and obtained consent from interested participants. The experimenter then took a digital photograph of each participant's face to be displayed in the online questionnaires to assist with participants' identification of their classmates. A few days later, participants received e-mail with a link to the Time 1 questionnaire. The questionnaire asked participants to complete demographic variables as well as several selfassessments of mate value. Next, participants completed partner assessments of mate value for all the opposite-sex individuals in their section who consented to be in the study. For each oppositesex target, the online questionnaire presented several mate value items along with the first name, last initial, and photograph of the partner. The presentation of the opposite-sex targets was ordered randomly.

During the 14th week of the semester, the participants received e-mail directing them to complete the Time 2 questionnaire. The self-assessments and partner assessments of mate value on the Time 2 questionnaire were identical to those on the Time 1 questionnaire, and the opposite-sex targets were again ordered randomly and presented with their first name, last initial, and photograph.

Materials. Participants completed several measures of mate value about themselves (self-assessments) and about each of the opposite-sex individuals in their group (partner assessments). Means, standard deviations, and alphas for the three classic measures and two relational factors are presented in Table 2 for both the self-assessment and partner assessment versions of these scales at Time 1 and Time 2. Alphas were calculated across all reports prior to bin assignment (see Analysis Strategy section below) and thus indicate how well all the items within the construct hung together.

The three classic mate value measures were taken from the prior evolutionary and social exchange literatures on the topic: six items from the Fletcher et al. (1999) attractiveness/vitality scale (adventurous, nice body, outgoing, sexy, attractive, and good lover), six items from the Fletcher et al. status/resources scale (good job [or potential to achieve], financially secure [or potential to achieve], nice house or apartment [or potential to achieve], successful [or potential to achieve], well dressed, intelligent), and six items from the Landolt et al. (1995) popularity mate value measure ("Members of the opposite sex that [name] $]^{2}$ likes tend to like him/her back," "Members of the opposite sex notice [name]," "[name] receives many compliments from members of the opposite sex,"

\footnotetext{
${ }^{1}$ In addition to the 129 , three participants completed the questionnaires but were excluded from analyses because they reported at Time 1 a " 1 " or a "2" to the item "I am exclusively attracted to members of the opposite sex" on a 1 (strongly disagree) to 9 (strongly agree) scale. In addition, participants from two small group sections were not included in the analyses reported herein because they were involved in a special program and knew each other from outside class, and participants from one small group section could not be analyzed because there were no men in the group.

2 [name] indicates that the computer program inserted (a) the first name and last initial of the target for the partner assessment of mate value and (b) "I" or "me" for the self-assessment of mate value (along with other minor grammatical changes).
} 
Table 2

Descriptive Statistics, Study 2

\begin{tabular}{|c|c|c|c|c|c|c|}
\hline \multirow[b]{2}{*}{ Construct } & \multicolumn{3}{|c|}{$\begin{array}{c}\text { Time } 1 \\
(2 \text { weeks) }\end{array}$} & \multicolumn{3}{|c|}{$\begin{array}{c}\text { Time } 2 \\
\text { (14 weeks) }\end{array}$} \\
\hline & $M$ & $S D$ & $\alpha$ & $M$ & $S D$ & $\alpha$ \\
\hline \multicolumn{7}{|c|}{ Self-assessments } \\
\hline \multicolumn{7}{|c|}{ Classic mate value measures } \\
\hline Vitality/attractiveness & 6.37 & 1.31 & .85 & 6.46 & 1.27 & .87 \\
\hline Status/resources & 7.25 & 0.97 & .78 & 7.30 & 1.10 & .90 \\
\hline Popularity & 5.28 & 1.63 & .89 & 5.61 & 1.74 & .92 \\
\hline \multicolumn{7}{|c|}{ Relational mate value measures } \\
\hline Satisfaction factor & 7.40 & 1.17 & .93 & 7.37 & 1.26 & .96 \\
\hline Values/respect factor & 7.74 & 1.08 & .90 & 7.61 & 1.16 & .94 \\
\hline
\end{tabular}

Classic mate value measures

Partner assessments

Vitality/attractiveness

Status/resources

Popularity

$\begin{array}{llllll}4.94 & 1.59 & .90 & 5.22 & 1.39 & .89\end{array}$

$\begin{array}{llllll}6.03 & 1.44 & .93 & 6.16 & 1.29 & .92\end{array}$

$\begin{array}{llllll}4.46 & 1.79 & .96 & 4.97 & 1.54 & .96\end{array}$

Relational mate value measures

Satisfaction factor

$\begin{array}{llllll}4.23 & 2.01 & .96 & 4.77 & 1.66 & .95\end{array}$

Values/respect factor

$\begin{array}{llllll}5.67 & 1.70 & .95 & 5.87 & 1.36 & .94\end{array}$

Note. $\quad N=125$ for Time 1 self-assessments, $N=597$ for Time 1 partner assessments; $N=122$ for Time 2 self-assessments, $N=570$ for Time 2 partner assessments.

"[name] receives sexual invitations from members of the opposite sex," "Members of the opposite sex are attracted to [name]," "[name] can have as many sexual partners as he/she chooses"). Participants completed the vitality/attractiveness and status/resources items on a scale from 1 (not at all) to 9 (extremely), and they completed the popularity items on a scale from 1 (strongly disagree) to 9 (strongly agree). Also, for exploratory purposes, participants completed six items from the Fletcher et al. warmth/ trustworthiness scale (understanding, supportive, considerate, kind, good listener, and sensitive) on a scale from 1 (not at all) to 9 (extremely).

We derived a new relational mate value measure from the close relationships literature (e.g., Fletcher et al., 2000; Rusbult et al., 1998) and the essay findings from Study 1 (e.g., emphasis on values and respect). We administered 14 items, and a factor analysis of the partner assessment version of these items (principal axis factoring with promax rotation) followed by a parallel analysis (Fabrigar, Wegener, MacCallum, \& Strahan, 1999) suggested two factors. The first we labeled a satisfaction factor, and the second we labeled a values/respect factor. Table 3 displays the partner assessment versions of these items, along with their factor loadings; the instructions asked participants to imagine that they were in a romantic relationship with the partner as they completed the items. The classic versus relational distinction is a theoretical one; the social relations model results below address the extent to which each construct is in reality trait-like (i.e., target variance) or dyadic (i.e., relationship variance).

To create the self-assessment version of the scale, we made appropriate grammatical changes to each item. Furthermore, each self-assessment item was preceded by the phrase "My romantic partners would say that ...,", and the instructions read: "The term 'my romantic partners' refers to your romantic partners in general (past, present, and future), not just your current partner." For example, the partner assessment item "[name] fulfills me in ways that other potential partners could not" was transformed into the self-assessment item "My romantic partners would say that I fulfill them in ways that other potential partners could not." Participants completed the relational mate value items on a scale from 1 (strongly disagree) to 9 (strongly agree).

We collected the second, end-of-semester assessment to examine how the pattern of variances shifted as participants got to know each other better. To verify that some participants did, in fact, get to know each other better between Time 1 and Time 2, we administered the following items at both time points: "I feel like I know [name] extremely well," "I know a lot about [name]," "[name] and I have spent a lot of time together," and "I would consider [name] a close friend." Participants' agreement with each of these items increased between Time 1 and Time 2 ( $t \mathrm{~s}>5.33$, $p s<.001)$, and variability on each item also increased between Time 1 and Time 2 (Levine's test $F \mathrm{~s}>8.15, p \mathrm{~s}<.005$ ). In other words, these data suggest that a critical difference between the two assessments was that some dyads had gotten to know each other better (whether inside or outside the classroom) at Time 2 than at Time 1.

Analysis strategy. The data were organized within a multilevel modeling framework, wherein each row of data represented one participant's rating of one partner. Initially, there were two records for each dyad (e.g., Betty's rating of Dane, Dane's rating of Betty). However, to separate relationship variance from error variance in the variance partitioning analyses, each of the five constructs was split randomly into two "bins" (i.e., the items "outgoing," "nice body," and "attractive" were averaged to form one bin for attractiveness/vitality, and the items "sexy," "good lover," and "adventurous" formed the second bin for attractiveness/vitality). The two bins were placed on separate rows in the data set; thus each dyad was now represented by four rows (e.g., Betty's Bin 1 and Bin 2 ratings of Dane, Dane's Bin 1 and Bin 2 ratings of Betty). ${ }^{3}$ Appendix B presents example SAS code for the social relations model analyses.

The data were analyzed with a blocked social relations model design. This design estimates the variances attributable to the perceiver, the target, the relationship, and error for each construct. Each of the nine small class groups was run in a separate analysis, producing nine sets of perceiver, target, relationship, and error variance estimates for men and nine sets of estimates for women. (The statistical program would not converge if all nine groups were estimated simultaneously.)

\section{Results}

Variance partitioning. Variance percentages are presented in Table 4 averaged across the nine groups. Descriptively speaking, the largest proportion of the variance was perceiver variance $(41 \%$ averaged across the five constructs at Time 1 and Time 2), which indicates that participants reported consistent ratings across targets

\footnotetext{
${ }^{3}$ It is largely unknown how the random assignment of items to bins could affect the results. Therefore, we actually ran two versions of all analyses using two different randomly generated pairs of bins (bins Version 1 and bins Version 2). Across all analyses, the difference in perceiver, target, and relationship variance estimates between the two bin versions averaged a mere $2.9 \%$ in Study 1 and $2.6 \%$ in Study 2 . Therefore, results in Studies 2 and 3 are presented averaged across the two bin versions.
} 
Table 3

Relational Mate Value Items, Studies 2 and 3

\begin{tabular}{lcc}
\multicolumn{1}{c}{ Item } & $\begin{array}{c}\text { Satisfaction } \\
\text { factor loading }\end{array}$ & $\begin{array}{c}\text { Values/respect } \\
\text { factor loading }\end{array}$ \\
\hline 1. [name] would be a desirable mate for me. & $\mathbf{9 5}$ & -.06 \\
2. I am sexually attracted to [name]. & $\mathbf{. 9 5}$ & -.15 \\
3. [name] fulfills me in ways that other potential & $\mathbf{8 9}$ & .02 \\
partners could not. & & .04 \\
4. Our relationship is better than others' & $\mathbf{8 8}$ & .08 \\
romantic relationships. & $\mathbf{. 8 4}$ & \\
5. [name] would be a valuable mate for me. & $\mathbf{. 3 3}$ \\
6. Our relationship does a good job of fulfilling & $\mathbf{. 9}$ & .09 \\
my needs for intimacy, companionship, etc. & -.07 & .12 \\
7. I really like [name]. & -.06 & $\mathbf{. 9 4}$ \\
8. [name] has good values. & .00 & $\mathbf{. 9 3}$ \\
9. [name] treats me as an equal. & -.05 & $\mathbf{. 9 2}$ \\
10. [name] shows a high level of respect for me. & .00 & $\mathbf{. 9 2}$ \\
11. [name] has strong morals. & .22 & $\mathbf{. 8 5}$ \\
12. [name] would make a good parent. & .28 & $\mathbf{. 6 8}$ \\
13. [name] is there for me when I need him/her. & & $\mathbf{. 6 4}$ \\
14. My family and friends get along with [name]. & & \\
\hline
\end{tabular}

Note. The instructions read: "For the following group of items, imagine that you are in a romantic relationship with [name]. Please rate the extent to which you agree with the following statements about [name]." Factor loadings greater than .3 are bolded.

on a given construct. For example, some participants generally saw targets as high in vitality/attractiveness, whereas other participants generally saw targets as low in vitality/attractiveness. These substantial perceiver variances are consistent with both (a) prior work demonstrating large actor effects of individual difference variables (e.g., self-esteem, neuroticism) predicting relationship constructs (McNulty, 2013; Murray et al., 2000) and (b) the notion that some people are more selective than others when rating potential partners' romantic desirability (Eastwick et al., 2007; Todd et al., 2007). Target variance was small to medium in size (13\%), which indicates that participants tended to achieve modest agreement about targets' attractiveness, status, popularity, and relational mate value. Relationship variance was strong (28\%), which means that participants rated targets as uniquely high (or low) in attractiveness, status, popularity, and relational mate value, above and beyond perceiver and target variance. Error variance comprised the remaining variance $(18 \%)$.

In accordance with standard social relations model hypothesistesting approaches (Kenny et al., 2006), we conducted hypothesis tests on the raw target and relationship variance estimates calculated for each group. Separate estimates were calculated for each of the five constructs at both time points for both men and women. The total number of variance estimates was 360: two sexes $\times$ two variance types (target vs. relationship) $\times$ five constructs $\times$ nine groups $\times$ two time points. Multilevel modeling accounted for the nesting of estimate within construct within group within time point; the intercept was permitted to vary randomly at each level.

Hypothesis 1 was that participants would exhibit more relationship variance than target variance overall. When analyzed across all 360 estimates, this hypothesis was supported, $\beta=.23, t(269)=$ $4.98, p<.001 .^{4}$ This difference between target and relationship variance remained significant if we examined both time points separately: Time $1, \beta=.15, t(134)=2.27, p=.025$; and Time 2, $\beta=.37, t(134)=5.51, p<.001$. When broken down separately by construct, relationship variance exceeded target variance at
Time 1 for status/resources, $\beta=.28, t(26)=2.38, p=.025$, and for the values/respect relational factor, $\beta=.38, t(26)=3.17, p=$ .004. At Time 2 , relationship variance exceeded target variance for status/resources, $\beta=.27, t(26)=2.26, p=.033$; popularity, $\beta=$ $.38, t(26)=2.08, p=.047$; the satisfaction relational factor, $\beta=$ $.52, t(26)=3.36, p=.002$; and the values/respect relational factor, $\beta=.51, t(26)=3.41, p=.002$. We also used a dummy code to group the constructs according to the classic (vitality/ attractiveness, status/resources, popularity) versus relational (satisfaction, values/respect) distinction. If we examine these two groupings separately, relationship variance only failed to exceed target variance for classic constructs at Time $1, \beta=.04, t(80)=$ $0.43, p=.667$; relationship variance exceeded target variance for the classic constructs at Time $2, \beta=.27, t(80)=3.20, p=.002$, and for the relational constructs at both Time $1, \beta=.31, t(53)=$ $3.29, p=.002$, and Time $2, \beta=.52, t(53)=4.75, p<.001$.

Was relationship variance more pronounced than target variance for relational constructs relative to classic constructs (Hypothesis $2)$ ? Yes. The Construct Type (classic vs. relational) $\times$ Variance Type (target vs. relationship) interaction was significant overall, $\beta=.12, t(268)=2.73, p=.007$. Separately by time point, the interaction was significant at Time $1, \beta=.13, t(133)=2.06, p=$ .041 , and marginally significant at Time $2, \beta=.12, t(133)=1.81$, $p=.073$. In other words, the relative predominance of relationship variance to target variance was stronger for the relational measures

\footnotetext{
${ }^{4}$ This finding was significantly moderated by participant sex, $\beta=-.10$, $t(267)=-2.08, p=.038$. For women's reports, relationship variance exceeded target variance, $\beta=.13, t(89)=3.01, p=.003$, but this difference was stronger for men's reports, $\beta=.32, t(89)=6.24, p<.001$. Target variance did not differ for men and women, $\beta=.00$, $t(170)=-0.04, p=.970$, but men revealed more relationship variance than women, $\beta=-.19, t(170)=-2.87, p=.005$. Sex did not moderate any of the other variance partitioning findings.
} 
Table 4

Variance Partitioning (by Percent), Study 2

\begin{tabular}{|c|c|c|c|c|c|c|}
\hline \multirow[b]{2}{*}{ Construct } & \multicolumn{3}{|c|}{ Time 1 ( 2 weeks $)$} & \multicolumn{3}{|c|}{ Time 2 (14 weeks) } \\
\hline & Perceiver & Target & Relationship & Perceiver & Target & Relationship \\
\hline \multicolumn{7}{|c|}{ Classic mate value measures } \\
\hline Vitality/attractiveness & 32.5 & 22.3 & 20.2 & 28.0 & 17.6 & 27.9 \\
\hline Status/resources & 38.0 & 7.5 & 27.1 & 53.2 & 4.4 & 20.6 \\
\hline Popularity & 34.9 & 25.5 & 25.3 & 29.5 & 17.9 & 37.7 \\
\hline \multicolumn{7}{|c|}{ Relational mate value measures } \\
\hline Satisfaction factor & 47.8 & 14.6 & 28.2 & 40.3 & 11.7 & 34.1 \\
\hline Values/respect factor & 51.1 & 6.4 & 26.6 & 50.0 & 5.7 & 30.9 \\
\hline \multicolumn{7}{|l|}{ Averages } \\
\hline Classic measures & 35.1 & 18.4 & 24.2 & 36.9 & 13.3 & 28.7 \\
\hline Relational measures & 49.5 & 10.5 & 27.4 & 45.2 & 8.7 & 32.5 \\
\hline
\end{tabular}

Note. Error variance is the difference between $100 \%$ and the sum of the perceiver, target, and relationship percentages in each row at each time point.

of mate value (a difference of $\sim 20 \%$; see Table 4 ) rather than the classic measures of mate value $(\sim 10 \%)$.

Finally, we examined whether target and relationship variance changed between Time 1 and Time 2 (Hypothesis 3). The relationship variance percentage increased between Time 1 and Time 2 for both classic and relational constructs, but neither increase was significant. However, target variance decreased between Time 1 and Time 2 for classic constructs, $\beta=-.23, t(80)=-2.47, p=$ .016 , and marginally for relational constructs, $\beta=-.14$, $t(53)=-1.67, p=.101$. In other words, participants achieved less consensus about their classmates over time; although the measures of mate value that we assessed did distinguish people who have high versus low mate value, this distinction faded significantly with increasing acquaintance.

Auxiliary analyses. Participants also completed warmth/ trustworthiness ratings of their classmates, a construct that has features in common with both the classic and relational measures. Variance partitioning on this construct generally resembled the relational measures: Perceiver variance was $39.5 \%$ at Time 1 and $49.4 \%$ at Time 2, target variance was $5.5 \%$ at Time 1 and $4.5 \%$ at Time 2, and relationship variance was $33.8 \%$ at Time 1 and $29.9 \%$ at Time 2. Relationship variance exceeded target variance at both
Time $1, \beta=.43, t(26)=2.82, p=.009$, and Time $2, \beta=.49$, $t(26)=3.28, p=.003$. Also, we tested the possibility that the variance partitioning findings for the relational mate value measures were driven by judgments of warmth/trustworthiness. Specifically, we conducted variance partitioning analyses on the satisfaction and respect/values factors controlling for warmth/ trustworthiness at both time points. Results did not change appreciably: Perceiver variance for the satisfaction and respect/ values factors was $44.4 \%$ (i.e., $3.0 \%$ lower), target variance was $8.7 \%$ (i.e., $0.9 \%$ lower), and relationship variance was $27.2 \%$ (i.e., $2.8 \%$ lower). In short, even though the variance partitioning findings for warmth/trustworthiness were similar to the relational mate value measure findings, subtracting the portion of these constructs that overlap still permits the inference that our participants' projections of relationship quality were primarily dyadic.

Given that most prior research on mate value has used selfreports as measures of mate value, we explored how participants' self-assessments on the same five central mate value variables dovetailed with the social relations model approach. The first pair of columns in Table 5 reports the correlations between participants' self-assessments and their actor effects; for example, do participants who see themselves as high in vitality/attractiveness

Table 5

Correlations Between Mate Value Self-Assessments and Partner Assessments, Study 2

\begin{tabular}{|c|c|c|c|c|c|c|}
\hline \multirow[b]{2}{*}{ Construct } & \multicolumn{2}{|c|}{ Actor effects } & \multicolumn{2}{|c|}{ Partner effects } & \multicolumn{2}{|c|}{ Similarity effects } \\
\hline & Time 1 & Time 2 & Time 1 & Time 2 & Time 1 & Time 2 \\
\hline \multicolumn{7}{|c|}{ Classic mate value measures } \\
\hline Vitality/attractiveness & -.03 & $.14^{*}$ & $.22^{* * * *}$ & $.19^{* * * *}$ & $-.12^{* * * *}$ & -.05 \\
\hline Status/resources & .05 & $.21^{* * *}$ & -.04 & -.03 & -.03 & .00 \\
\hline Popularity & -.01 & .08 & $.20^{* * * *}$ & $.20^{* * * *}$ & .04 & .04 \\
\hline \multicolumn{7}{|c|}{ Relational mate value measures } \\
\hline Satisfaction factor & -.08 & $.13^{\dagger}$ & $.09^{* *}$ & $.07^{\dagger}$ & -.05 & .03 \\
\hline Values/respect factor & .11 & $.23^{* * * *}$ & .02 & -.01 & -.01 & -.01 \\
\hline
\end{tabular}

Note. Actor effects indicate correlations between the participant's self-assessment on a measure and his or her partner assessment ratings of targets on that measure. Partner effects indicate correlations between the participant's self-assessment on a measure and targets' partner assessment ratings of him or her on that measure. Similarity effects indicate correlations between (a) the absolute value of the difference between the participant's and target's self-assessment on a measure and (b) the participant's partner assessment rating of the target on that measure (controlling for the two self-assessment main effects).

${ }^{\dagger} p \leq .10 .{ }^{*} p \leq .05 .{ }^{* *} p \leq .01 .{ }^{* * *} p \leq .001$. 
also rate others as high in vitality/attractiveness? None of the five correlations was significant at Time 1 , but four of five were at least marginally significant at Time 2 . That is, there was a modest tendency for participants to assimilate others to their self-reports at Time 2: Participants who saw themselves as high in vitality/ attractiveness, status/resources, and relational mate value tended to see targets as similarly high in those same variables.

The second pair of columns in Table 5 reports the correlations between participants' self-assessments and their partner effects; these correlations indicate whether participants' self-assessments are accurately attuned to the targets' consensus ratings about them. Participants' self-assessments did in fact correlate with their partner effects for vitality/attractiveness, popularity, and (weakly) the satisfaction relational mate value factor at Time 1 and Time 2 . Participants' self-assessments were unrelated to their partner effects for status/resources and for the values/respect relational mate value factor. Recall that for status/resources and the values/respect relational mate value factor, target variance was quite weak $(\sim 6 \%)$; therefore, the partner effects for these variables are unlikely to be reliable. Nevertheless, partner effects did significantly correlate with self-assessments for the three variables demonstrating a meaningful (i.e., $10 \%$ or more) amount of target variance, indicating convergent validity.

The existence of relationship variance is consistent with the suggestion that various idiosyncratic factors cause participants to rate targets as uniquely high or low on these mate value variables. However, one possible source of relationship variance-actual similarity-potentially follows from the classic perspective on mate value: Participants could be using their self-ratings as a guide to settle for the best partner they could realistically obtain. This prediction is reminiscent of the matching hypothesis (Eastwick \& Buck, in press; Kalick \& Hamilton, 1986; Taylor, Fiore, Mendelsohn, \& Cheshire, 2011); if actual similarity in self-ratings on a quality predicts mate value judgments on the quality, then relationship variance could be driven in part by such a similarity-based settling process. For example, participants could rate a target as especially high in vitality/attractiveness to the extent that the participant's self-assessment and the target's self-assessment on vitality/attractiveness are similar. However, as displayed in the last pair of columns in Table 5, there was not much support for this hypothesis. Significant similarity effects (i.e., the absolute value of the difference between the participant's assessment and the target's self-assessment controlling for the two self-assessment main effects; Griffin, Murray, \& Gonzalez, 1999) emerged in only one out of 10 hypothesis tests, and only six out of 10 were even in the predicted negative direction. A limitless number of idiosyncratic sources (i.e., all conceivable actor $\times$ partner effects) combine to produce relationship variance, but actual similarity appears to be a weak contributor to the large proportion of relationship variance that we documented.

\section{Discussion}

Participants in this study rated their opposite-sex classmates on several measures of mate value at 2 weeks and 14 weeks into the semester. On average, they achieved modest consensus about their classmates' vitality/attractiveness, status/resources, and popularity (i.e., classic mate value measures); they also revealed some consensus regarding who was or was not likely to be a good relation- ship partner (i.e., relational mate value measures). However, as predicted, relationship variance typically exceeded target variance: The tendency for participants to see their classmates as uniquely high or low in mate value was stronger than their tendency to achieve consensus. The relative dominance of relationship variance to target variance was stronger for the relational measures of mate value than the classic measures of mate value. In other words, classic mate value constructs were more relational than trait-like, but this effect was even stronger for the relational mate value measures. Variance partitioning findings for warmth/trustworthiness resembled the relational measures, with relationship variance exceeding target variance at both time points.

Auxiliary analyses examined how self-assessments of mate value intersected with the current social relations model approach. First, actor effect correlations revealed that people tended to use their self-assessments as a basis for assimilation, especially at Time 2 (e.g., participants who saw themselves as high in attractiveness/vitality tended to see others as having attractiveness/ vitality). Second, partner effect correlations for constructs exhibiting meaningful consensus ( $10 \%$ or more) revealed some evidence for convergent validity: Targets' self-assessments correlated with others' ratings about them for vitality/attractiveness, popularity, and the satisfaction factor. Third, results revealed few similarity effects. For example, two participants who rated themselves similarly in relational mate value were no more or less likely to see each other as especially desirable partners. These latter findings are consistent with other research revealing weak effects for actual similarity in initial attraction contexts (Tidwell et al., 2013). Thus, it seems unlikely that the current results can be explained by appealing to the matching hypothesis (Berscheid, Dion, Walster, \& Walster, 1971). Rather, participants idiosyncratically disagree about who is and is not a desirable dating partner, and deviations from perfect matching occur because people are able to find partners who are uniquely desirable to them (Eastwick \& Buck, in press).

Another novel feature of these data is that they enabled us to explore whether target and relationship variance changed over time. Results revealed that target variance decreased between Week 2 and Week 14 of the semester. In other words, participants achieved consensus in their assessments of the mate value of specific targets at initial acquaintance, but as they had a chance to get to know the targets better, their ability to differentiate low from high mate value targets weakened. On the surface, this finding seems somewhat counterintuitive: As people acquire more information about a person, it seems plausible that they would come closer to discovering "truth" and thus achieve more consensus. In fact, this hypothesis has been examined extensively in the personality domain, where several studies have revealed that consensus regarding the Big Five does not change with increasing levels of acquaintance (Kenny et al., 1994). Rather, in initial interaction settings, people achieve consensus because they draw from shared stereotypes about a target, and with increasing acquaintance, consensus remains steady as people form impressions based on the target's actual behaviors (Kenny, 2004). But if people's romantic interpretations of a target's behaviors are highly idiosyncratic (e.g., Cassandra and Betty disagree about whether Dane's enthusiastic contributions to class are annoying or endearing) - more idiosyncratic than personality judgments (e.g., Cassandra and Betty disagree about whether Dane's behaviors connote extraversion)- 
then consensus about romantic constructs should decrease as behavioral information accumulates over time.

Nevertheless, it would be informative to see whether this trend continues in a sample of individuals who have known each other for a longer period beyond the "closed field" classroom setting. Therefore, in Study 3, we examined the "open field" context of people's freely chosen opposite-sex acquaintances, including established relationship partners. For this study, we used a design in which focal persons nominated and completed questionnaires about several opposite-sex acquaintances (i.e., informants; Vazire, 2006; Woodruffe, 1984), and we then contacted those acquaintances to complete questionnaires about the focal person. Although this one-with-many design is not a complete round-robin or blocked design, it nevertheless permits the calculation of all sources of variance (Kenny et al., 2006; Marcus, Kashy, \& Baldwin, 2009).

We anticipated that we would replicate the Study 2 pattern such that relationship variance would exceed target variance, especially for the relational mate value measures. Furthermore, given that the Study 3 opposite-sex acquaintances had gotten to know one another in different contexts (not just a single classroom) and over a longer period, we anticipated that the difference between target variance and relationship variance could be dramatic (Branje et al., 2002; Giblin \& Lakey, 2010; Lakey et al., 1996). That is, target variance among these acquaintances could be quite low, whereas relationship variance could be quite large.

\section{Study 3}

\section{Method}

Participants. Participants consisted of 92 focal persons (30 men, 62 women) and 252 informants ( 171 men, 81 women). The average number of informants per focal person was 2.7 , the median was 3 , and the range was $2-6$. The focal persons took part in the study in partial fulfillment of a course requirement, and the informants completed the study to earn one $\$ 125$ raffle entry for themselves and one for their focal person. The 344 participants were 19.6 years old $(S D=1.0)$ on average; $2 \%$ of the sample identified as African American/Black, 5\% as Asian/Pacific Islander, $16 \%$ as Hispanic, and $77 \%$ as White/Caucasian. Fifty-two percent reported that they currently had a romantic partner.

Procedure. The focal persons arrived at the laboratory and first completed demographic variables and the self-assessments of mate value on a computer. Next, the instructions invited the focal person to nominate up to 10 opposite-sex peers whom he or she knew personally (i.e., informants). The instructions indicated that the informants should be approximately the same age as the focal person (i.e., a peer) and not a family member. Focal persons were also encouraged to provide an e-mail address for each informant with the understanding that we would e-mail the informant with a link to a questionnaire about the focal person; for every informant who completed a questionnaire, both the focal person and the informant would receive one entry into the $\$ 125$ raffle. The instructions also reminded focal persons that their responses and the responses of their nominated informants would remain completely confidential. Finally, focal persons completed partner assessments of mate value about each of the nominated informants.
Between 1 and 3 days after the focal person completed his or her questionnaire, the experimenter e-mailed each informant. The e-mail notified the informants that the focal person had nominated them to participate in a brief online survey and that they could earn a raffle entry by completing the questionnaire. The informants received one invitational e-mail and one reminder e-mail. When the informants clicked on the link in the e-mail, they completed a set of demographic questions, the self-assessments of mate value, and the partner assessments of mate value about the focal person.

Materials. Means, standard deviations, and alphas for the three classic measures and two relational factors are presented in Table 6 for both the self-assessment and partner assessment versions of these scales separately for focal persons and informants. Focal persons and informants completed the same three classic mate value measures (vitality/attractiveness, status/resources, and popularity) and the same two measures of relational mate value (satisfaction and values/respect) as in Study 2. They also completed the Study 2 measure of warmth/trustworthiness. In this study, participants completed items on a scale from 1 (strongly disagree) to 7 (strongly agree).

For descriptive purposes, we also asked informants how close they were to the focal person on a scale from 1 (not close) to 5 (very close), how well they knew the focal person on a scale from 1 (very little) to 5 (very well), and how many months they had known the focal person. Informants on average indicated that they were moderately close $(M=3.1, S D=1.3)$ to the focal persons and knew them moderately well $(M=3.1, S D=1.4)$; they had known the focal person for approximately 3 years on average $(M=36.5$ months, $S D=32.2)$.

Analysis strategy. As in Study 2, the data were organized such that each dyad was represented by four rows in the data set (e.g., Betty's Bin 1 and Bin 2 rating of Dane, Dane's Bin 1 and Bin 2 rating of Betty). However, the current design is not a blocked design as in Study 2 but rather a reciprocal, one-with-many de-

Table 6

Descriptive Statistics, Study 3

\begin{tabular}{|c|c|c|c|c|c|c|}
\hline \multirow[b]{2}{*}{ Construct } & \multicolumn{3}{|c|}{ Focal persons } & \multicolumn{3}{|c|}{ Informants } \\
\hline & $M$ & $S D$ & $\alpha$ & $M$ & $S D$ & $\alpha$ \\
\hline \multicolumn{7}{|c|}{ Self-assessments } \\
\hline \multicolumn{7}{|c|}{ Classic mate value measures } \\
\hline Vitality/attractiveness & 5.33 & 0.86 & .80 & 5.46 & 0.93 & \\
\hline Status/resources & 5.94 & 0.65 & .76 & 5.84 & 0.72 & \\
\hline Popularity & 4.58 & 1.26 & .88 & 4.74 & 1.21 & \\
\hline \multicolumn{7}{|c|}{ Relational mate value measures } \\
\hline Satisfaction factor & 6.38 & 0.65 & .88 & 6.04 & 0.81 & .8 \\
\hline Values/respect factor & 6.35 & 0.62 & .83 & 6.19 & 0.68 & .7 \\
\hline
\end{tabular}

Partner assessments

Classic mate value measures

$\begin{array}{llllllll}\text { Vitality/attractiveness } & & 5.05 & 1.27 & .89 & 5.29 & 1.15 & .83\end{array}$

$\begin{array}{lllllll}\text { Status/resources } & 5.52 & 1.29 & .95 & 5.88 & 0.94 & .84\end{array}$

$\begin{array}{lllllll}\text { Popularity } & 4.66 & 1.30 & 92 & 4.85 & 1.13 & 81\end{array}$

Relational mate value measures

Satisfaction factor

$\begin{array}{llllll}4.38 & 1.52 & .95 & 4.99 & 1.47 & .92\end{array}$

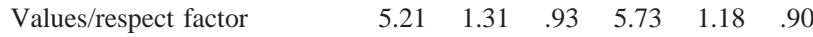

Note. $\quad N=92$ for focal person self-assessments, $N=252$ for focal person partner assessments, target self-assessments, and target partner assessments. 
sign - a specialized form of the social relations model (Kenny et al., 2006). In this case, participants were organized into groups consisting of a focal person (the one) and their nominated informants (the many). Variance estimates must be calculated across the entire data set in a one-with-many design, not within each group as in a blocked design, as each one-with-many group contains ratings from only one "perceiver" and ratings of only one "target." In other words, perceiver variance estimates derive from the ratings generated by focal persons (who rate several informants), and target variance estimates derive from the ratings generated by the informants (several of whom rate the same focal person). For this reason, to merit inclusion in the data analyses, at least two informants needed to complete reports about the focal person. ${ }^{5}$ Appendix $\mathrm{C}$ presents example SAS code for the social relations model analyses.

When focal persons rate many informants, one can obtain estimates for a perceiver variance, a relationship + target variance, and an error variance. When at least two informants rate a focal person, one can obtain estimates for a target variance, a relationship + perceiver variance, and an error variance. That is, the one-with-many design generates a combined relationship + target variance estimate for focal persons' reports and a combined relationship + perceiver variance estimate for informants' reports.

To handle these complexities, the perceiver, target, and relationship variance percentages were calculated as follows: The perceiver variance percentage reported in the analyses below is the perceiver variance estimate (provided by the focal persons) divided by the total of the three variances provided by the focal persons, and the target variance percentage is the target variance estimate (provided by the informants) divided by the total of the three variances provided by the informants (Marcus et al., 2009). To derive an estimate of focal persons' relationship variance, we subtract the target variance (generated by the informants' ratings) from the focal person's relationship + target variance estimate to generate a "clean" focal person relationship variance. To derive a clean estimate of informants' relationship variance, we subtract the perceiver variance (generated by the focal persons' ratings) from the target's relationship + perceiver variance to generate a clean target relationship variance. The relationship variance percentage reported below is the average of the focal persons' and informants' clean estimates (see Appendix C for a concrete numerical example).

\section{Results}

Variance partitioning. Variance percentages are presented in Table 7. As in Study 2, a substantial amount of variance was due to the actor $(29 \%)$, which indicates that some focal persons generally tended to rate informants high and others generally tended to rate informants low on a given mate value construct. Target variance was quite small on average $(4 \%)$, which suggests that informants achieved little to no consensus about focal persons' mate value. Relationship variance was extremely strong (46\%); focal persons and informants tended to rate each other as uniquely high or low on the various mate value constructs. Error variance comprised the remaining variance $(21 \%)$.

Hypothesis tests in Study 2 used the estimates produced by each group, but in the current study, only one set of estimates could be generated for each mate value construct. Therefore, we conducted
Table 7

Variance Partitioning (by Percent), Study 3

\begin{tabular}{lccc}
\hline \multicolumn{1}{c}{ Construct } & Perceiver & Target & Relationship \\
\hline Classic mate value measures & & & \\
$\quad$ Vitality/attractiveness & 26.5 & 5.9 & 42.5 \\
$\quad$ Status/resources & 39.4 & 0.0 & 42.1 \\
$\quad \begin{array}{l}\text { Popularity } \\
\text { Relational mate value measures }\end{array}$ & 26.8 & 7.5 & 32.5 \\
$\quad$ Satisfaction factor & 13.6 & 4.0 & 70.9 \\
$\quad$ Values/respect factor & 39.0 & 0.0 & 44.0 \\
Averages & & & \\
$\quad$ Classic measures & 30.9 & 4.5 & 39.0 \\
$\quad$ Relational measures & 26.3 & 2.0 & 57.4 \\
\hline
\end{tabular}

Note. Error variance is the difference between $100 \%$ and the sum of the perceiver, target, and relationship percentages in each row.

hypothesis tests using the variance estimates and standard errors produced by the SAS code (Kenny et al., 2006; see Appendix D for details). As in Study 2, we examined whether participants exhibited more relationship variance than target variance. Relationship variance exceeded target variance for all five constructs: vitality/ attractiveness $(z=3.08, p=.002)$, status/resources $(z=4.49, p<$ $.001)$, popularity $(z=2.22, p=.027)$, satisfaction relational factor $(z=4.58, p<.001)$, and values/respect relational factor $(z=5.63$, $p<.001)$. When estimates and standard errors were averaged across the three classic mate value constructs, relationship variance again significantly exceeded target variance $(z=3.07, p=.002)$. Also, relationship variance exceeded target variance when averaged across the two relational mate value factors $(z=4.79, p<$ $.001)^{6}$

As in Study 2, we wished to test whether relationship variance was stronger than target variance for relational constructs relative to classic constructs. The Construct Type $\times$ Variance Type interaction was significant $(z=2.72, p=.006)$. In other words, the relative predominance of relationship variance to target variance was stronger for the relational measures of mate value (a difference of $\sim 55 \%$; see Table 7 ) rather than the classic measures of mate value $(\sim 35 \%)$.

\footnotetext{
${ }^{5}$ In addition to the 92 focal persons who met these criteria, 55 received reports from only one informant, 94 received no responses from any informant, and 10 did not provide us with at least two usable e-mail addresses. One-way analyses of variance suggested that these four groups of (potential) participants did not significantly differ on any of the selfassessments of mate value ( $p s>.105)$. Similarly, multilevel regression analyses (to account for the nesting of informant within focal person) revealed that focal person partner assessments of mate value regarding the informants who completed the survey did not significantly differ from the informants who did not complete the survey $(p s>.202)$. Thus, the focal persons and informants that we analyzed did not differ in any obvious way from the focal persons and informants that we could not analyze. In addition, just as in Study 2, five focal persons were excluded from analyses because they reported a " 1 " or a " 2 " to the item "I am exclusively attracted to members of the opposite sex."

${ }^{6}$ Men's and women's reports did not differ significantly on either target variance or relationship variance for either classic or relational mate value constructs $(p s>.507)$. When broken down separately by construct, only one marginally significant difference emerged (out of 10): Men exhibited more relationship variance in their status/resources reports than women $(z=1.83, p=.067)$. In short, there was little evidence that the sexes differed in the variance partitioning of their mate value judgments.
} 
Auxiliary analyses. In Study 2, variance partitioning findings for warmth/trustworthiness revealed that relationship variance exceeded target variance, as with other constructs. This pattern was again supported by the Study 3 results: Perceiver variance was $31.8 \%$, target variance was $17.3 \%$, and relationship variance was $36.3 \%$, and the difference between relationship and target variance was marginally significant $(z=1.64$, $p=.100)$. Also, variance partitioning analyses on the satisfaction and respect/values factors revealed similar conclusions when controlling for warmth/trustworthiness: Perceiver variance for the satisfaction and respect/values factors was $23.8 \%$ (i.e., $2.5 \%$ lower), target variance was $2.1 \%$ (i.e., $0.1 \%$ higher), and relationship variance was $50.1 \%$ (i.e., $7.3 \%$ lower).

Focal persons indicated that they were currently involved in a romantic relationship with 28 of the 252 targets. It seems likely that the inclusion of romantic partners in the analysis would lower target variance and increase relationship variance, as romantic partners tend to rate each other as especially wonderful (Murray et al., 1996a). But to what extent is the current pattern of data driven by the presence of romantic partners among the targets? To examine this question, we reran the variance partitioning analyses after removing these 28 romantic partner informants. These analyses also required that we remove eight focal persons from the analysis, as their romantic partner was one of only two informant reports about them.

Variance partitioning results excluding the 28 romantic partners are presented in Table 8 . Removing romantic partners indeed increased target variance and decreased relationship variance, but the overall pattern changed little. Relationship variance did not significantly exceed target variance for vitality/attractiveness $(z=$ $1.09, p=.273$ ), but this difference was at least marginally significant for status/resources $(z=2.94, p=.003)$, popularity $(z=$ $1.82, p=.069)$, the satisfaction relational factor $(z=2.53, p=$ $.011)$, and the values/respect relational factor $(z=2.12, p=.034)$. Once again, when averaged across classic and relational constructs, relationship variance exceeded target variance (marginally) for classic constructs $(z=1.76, p=.074)$ and significantly for relational constructs $(z=2.36, p=.018)$. In summary, although the inclusion of romantic partners strengthened our predicted pattern of findings, our Study 3 data are not simply a story about the unique perceptions that romantic partners share of each other.

Table 8

Variance Partitioning (by Percent) With Romantic Partners Excluded, Study 3

\begin{tabular}{lccc}
\hline \multicolumn{1}{c}{ Construct } & Perceiver & Target & Relationship \\
\hline Classic mate value measures & & & \\
$\quad$ Vitality/attractiveness & 41.1 & 9.6 & 25.2 \\
$\quad$ Status/resources & 47.6 & 0.0 & 34.8 \\
$\quad \begin{array}{l}\text { Popularity } \\
\text { Relational mate value measures }\end{array}$ & 27.7 & 10.8 & 33.2 \\
$\quad$ Satisfaction factor & 32.3 & 6.6 & 47.1 \\
$\quad$ Values/respect factor & 53.1 & 0.5 & 27.4 \\
Averages & & & \\
$\quad$ Classic measures & 38.8 & 6.8 & 31.1 \\
$\quad$ Relational measures & 42.7 & 3.5 & 37.2 \\
\hline
\end{tabular}

Note. Error variance is the difference between $100 \%$ and the sum of the perceiver, target, and relationship percentages in each row. $N=84$ focal persons and $N=216$ informants.
Also as in Study 2, we calculated the correlations between participants' self-reports and their actor effects and partner effects, and we explored possible similarity effects. These results are displayed in Table 9. Again, there was modest evidence for assimilation based on self-reports: All 10 actor effects were positive, and five were at least marginally significant. That is, participants who saw themselves highly on a particular mate value construct tended to see others highly on the same construct. Partner effect correlations tended to be weaker, with only two significant correlations emerging. Intriguingly, even though informants did not achieve any consensus about focal persons' status/resources (see Table 7), informants' self-reports correlated with the focal persons' judgments of informants' status/resources. As in Study 2, actual similarity effects were generally weak: One significant correlation emerged, but this correlation was in the opposite of the predicted direction (i.e., greater self-reported differences on popularity predicted informants' greater popularity judgments).

\section{Discussion}

In Study 3, participants completed mate value reports about several opposite-sex acquaintances whom they had known for approximately 3 years on average; this procedure contrasted with Study 2, in which previously unacquainted participants got to know each other over several months. Variance partitioning analyses replicated the central hypothesis tests from Study 2: Relationship variance was generally stronger than target variance, and this difference was larger for relational than classic measures of mate value. The inclusion of romantic partners among the opposite-sex acquaintances appeared to contribute to this pattern of data, as removing romantic partners from the analyses lowered relationship variance and increased target variance to a modest degree. Yet relationship variance consistently exceeded target variance even in a reduced data set that did not contain romantic partners. These findings suggest that as people get to know one another over time, current romantic partners are not the only perceivers who exhibit unique views of a particular target. Rather, opposite-sex acquaintances disagree about whether a target does or does not possess desirable qualities, and they similarly disagree about whether the target would or would not be a desirable relationship partner. Finally, auxiliary self-report analyses largely replicated Study 2: Results revealed more relationship than target variance for warmth/trustworthiness, several assimilation effects, a handful of partner effects, and no similarity-attraction effects.

Figure 1 presents the findings relevant to Hypotheses 1-3 across both Studies 2 and 3; support for all three hypotheses is evident in this display. Hypothesis 1 was that relationship variance would exceed target variance. All six pairs of bars trend in this direction, and in many cases this difference was enormous. In other words, even in cases where opposite-sex acquaintances achieve some level of consensus about one another's mate value, consensus is smaller than the unique variance present in participants' judgments. Hypothesis 2 was that the relative dominance of relationship variance to target variance would be stronger for the relational mate value measures (i.e., the right side of the figure) than the classic mate value measures (i.e., the left side of the figure). As evident in the figure, measures of mate value that focused on traits (i.e., classic measures) were more likely than measures that focused on relationship quality to exhibit consensus, although rela- 
Table 9

Correlations Between Mate Value Self-Assessments and Partner Assessments, Study 3

\begin{tabular}{|c|c|c|c|c|c|c|}
\hline \multirow[b]{2}{*}{ Construct } & \multicolumn{2}{|c|}{ Actor effects } & \multicolumn{2}{|c|}{ Partner effects } & \multicolumn{2}{|c|}{ Similarity effects } \\
\hline & $\begin{array}{c}\text { Focal } \\
\text { persons }\end{array}$ & Informants & $\begin{array}{c}\text { Focal } \\
\text { persons }\end{array}$ & Informants & $\begin{array}{c}\text { Focal } \\
\text { persons }\end{array}$ & Informants \\
\hline \multicolumn{7}{|c|}{ Classic mate value measures } \\
\hline Vitality/attractiveness & .10 & .07 & .02 & .05 & -.08 & -.01 \\
\hline Status/resources & $.21^{*}$ & .07 & $.21^{* * * *}$ & .03 & .01 & .00 \\
\hline Popularity & $.16^{\dagger}$ & .03 & .08 & $.19^{* *}$ & .02 & $.13^{*}$ \\
\hline \multicolumn{7}{|c|}{ Relational mate value measures } \\
\hline Satisfaction factor & .10 & $.14^{\dagger}$ & -.12 & -.09 & -.04 & .04 \\
\hline Values/respect factor & $.29^{* * *}$ & $.13^{\dagger}$ & -.02 & .02 & -.06 & .05 \\
\hline
\end{tabular}

Note. Actor effects indicate correlations between the participant's self-assessment on a measure and his or her partner assessment ratings of targets on that measure. Partner effects indicate correlations between the participant's self-assessment on a measure and targets' partner assessment ratings of him her on that measure. Similarity effects indicate correlations between (a) the absolute value of the difference between the participant's and target's self-assessment on a measure and (b) the participant's partner assessment rating of the target on that measure (controlling for the two self-assessment main effects).

${ }^{\dagger} p \leq .10 .{ }^{*} p \leq .05$. ${ }^{* *} p \leq .01 .{ }^{* * * *} p \leq .001$.

tionship variance was larger than target variance for trait measures in all cases. Hypothesis 3 was that target variance would tend to decrease and relationship variance would tend to increase over time. Indeed, as time passes from 2 weeks to 14 weeks to longterm acquaintance, relationship variance exceeds target variance by larger and larger margins. This pattern suggests that as people move from initial impressions to settings where they get to know opposite-sex others over time, consensus about desirable qualities that are intrinsic to the individual become diluted and overshadowed by unique variability in romantic evaluations.

\section{General Discussion}

The classic perspective on mate value suggests that people possess romantically desirable qualities to different degrees; that is, some people are more attractive, more intelligent, or more popular than others. Many of the findings in the current set of studies are consistent with this perspective. For example, Study 1 asked participants themselves to describe their own conceptualization of mate value, and many of them mentioned vitality/attractiveness and status/resources traits, two constructs that are highlighted extensively in the mate value literature (Fletcher et al., 1999; Symons, 1987). Furthermore, in an extension of prior research on initial impressions (Asendorpf et al., 2011; Back, Schmukle, \& Egloff, 2011), Study 2 participants who were just getting to know one another reached consensus with respect to several measures of mate value. That is, participants tended to agree on which of their opposite-sex classmates did and did not possess these desirable traits. They also achieved consensus re-

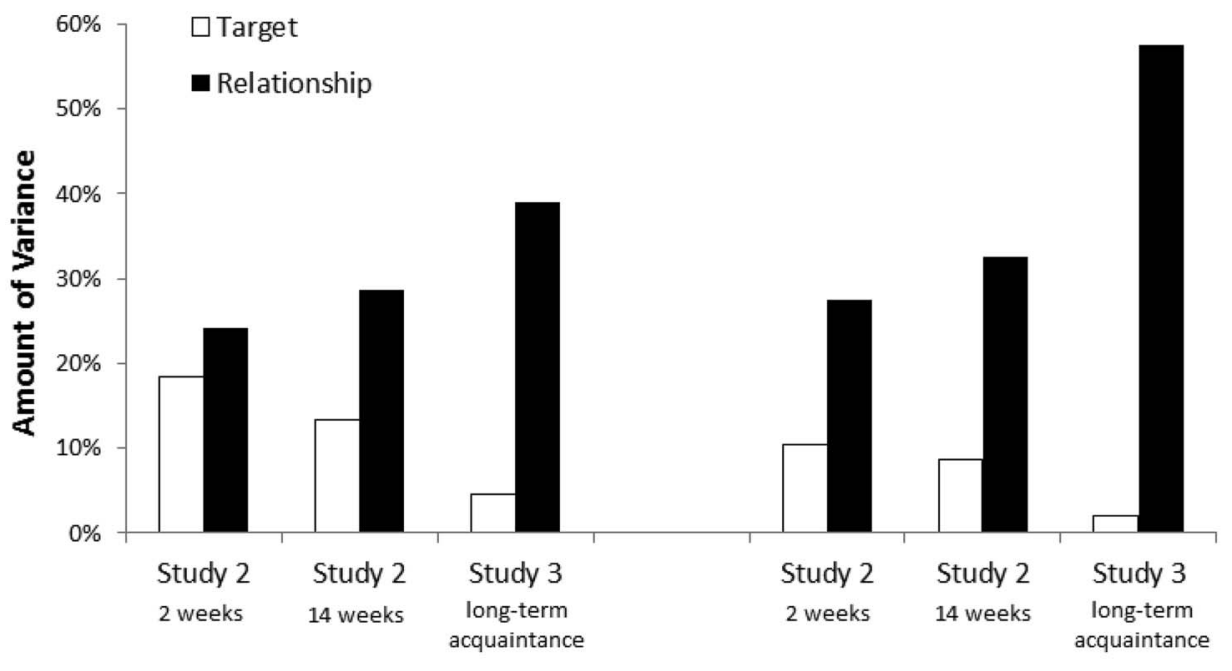

\section{Classic Mate Value Measures}

\section{Relational Mate Value Measures}

Figure 1. Target variances and relationship variances averaged across classic (left) and relational (right) mate value measures. Hypothesis 1 was that relationship variance would exceed target variance (black vs. white bars). Hypothesis 2 was that the difference between target variance and relationship variance would be larger for relational (right) than classic (left) measures. Hypothesis 3 was that the difference between target and relationship variance would become larger as time passes (left vs. middle vs. right bars within measure type). 
garding which of their classmates were popular with members of the opposite sex-another classic measure of mate value (Landolt et al., 1995). Even though consensus declined as participants got to know one another over time, they continued to exhibit some consensus with respect to vitality/attractiveness and popularity 14 weeks after meeting.

Yet several aspects of the current findings were consistent with our new relational perspective on mate value. One relational insight highlighted the utility of using judgments of projected romantic quality as a measure of mate value: Do people think that they would be more satisfied in a romantic relationship with some people instead of others? A second relational insight recommends the examination of the relative amounts of variance in romantic evaluation judgments due to the partner versus the relationship: Do people's romantic judgments primarily reveal consensus or uniqueness? Both of these alternative conceptualizations generated new knowledge about mate value. For example, participants in Study 1 mentioned relationship quality constructs very frequently in their mate value essays, and they also mentioned other relational concepts (e.g., values, respect) that were not well represented in the prior literature. We were able to incorporate these concepts into a new relational measure of mate value for use in Studies 2 and 3. On this new relational measure of mate value, on classic measures of mate value, and on judgments of warmth/trustworthiness (a hybrid of relational and classic measures), participants revealed large amounts of relationship variance with respect to their opposite-sex classmates (Study 2) and acquaintances (Study 3). That is, participants exhibited considerable uniqueness in their judgments of who was attractive, intelligent, and popular, and they strongly disagreed about who was likely to be a good relationship partner. When the Study 3 participants reported on opposite-sex individuals whom they had known for a considerable period, they reached very little consensus about these qualities and exhibited huge amounts of relationship variance. In summary, the new insights generated by the current data are as follows: Although consensus emerges on desirable qualities in initial impression settings, this consensus is weaker than the tendency for participants to see one another as uniquely desirable or undesirable, and over time, relationship variance grows while consensus declines.

\section{Implications and Future Directions}

People have a mating sociometer that is calibrated to their romantic successes and failures (Kavanagh et al., 2010; Kirkpatrick \& Ellis, 2001), and the evidence is strong that this sociometer is linked to other romantically relevant self-assessments (Kenrick et al., 1993; Kirsner et al., 2003; Regan, 1998b). We suggest, however, that this perspective omits a component of what mate value means in humans, a component that is better captured by assessments that take place among existing acquaintances and that involve judgments of relationship quality. To be sure, some people engage in sexual activity shortly after meeting one another, and mate value studies conducted in initial interaction settings should reveal important insights about such contexts (Back, Penke, Schmukle, Sachse, et al., 2011; Kavanagh et al., 2010; Todd et al., 2007). However, humans normatively take time to get to know one another before they pursue and initiate romantic liaisons (Eastwick, Morgan, et al., 2013; Kaestle \& Halpern, 2005). Because people often do not know what sort of relationship they want from someone (e.g., friendship, sex, romance, no relationship at all) until they have spent time getting to know him or her, time is a central element of many relationship formation and courtship theories (Altman \& Taylor, 1973; Eastwick, Morgan, et al., 2013; Finkel, Eastwick, Karney, Reis, \& Sprecher, 2012; Hazan \& Shaver, 1994; Huston et al., 1981; Knapp, 1984, L. C. Miller, Pedersen, \& Putcha-Bhagavatula, 2005). The prior literature on mate value does not link straightforwardly to these contexts. As additional work allows for more precise estimates of the degree of consensus about desirable traits in both initial impression and long-term acquaintance settings, quantitative evolutionary models (e.g., Todd \& Miller, 1999) can perhaps identify the romantic contexts in which consensus is and is not substantial enough for the trait to have affected ancestral reproductive outcomes.

Of course, self-assessments like those used in prior mate value research are certainly relevant to relationship functioning; actor effects abound for desirable qualities (Ellis et al., 2002), attachment style (Campbell et al., 2005), neuroticism (McNulty, 2013), self-esteem (Murray et al., 2000), and myriad other individual difference variables. In other words, people who are agreeable, secure, emotionally stable, and have high self-worth are more likely to report love for their partners and that they believe they are loved by their partners. In the current work, perceiver variance was large, which likely reflects the underlying influence of these individual difference variables-in principle, the sum of all actor effects (e.g., Dane's individual difference scores and all their interactions) would add up to perceiver variance (Kenny et al., 2006)

But assessed in isolation, actor effects of individual differences might not reflect underlying mate value but rather variability in the perceptual tools that people bring to relationships (e.g., Dane thinks everyone hates him, regardless of whether or not they do). If individuals possess an intrinsic mate value that can be perceived by others, then individual differences should predict who is more or less loveable, yet the collective magnitude of these partner effects remains unclear. On the one hand, partner effects do emerge for self-esteem (Murray, Bellavia, Rose, \& Griffin, 2003; Murray et al., 2000) and attachment anxiety (Campbell et al., 2005) such that the partners of low self-esteem or high-anxiety individuals report lower relationship quality. Indeed, we detected a nonzero amount of target variance for several of the mate value partner assessments among long-term acquaintances in Study 3, and this target variance could derive from such individual differences among our participants. On the other hand, partner effects of individual difference variables in relationships may be quite small on average (Dyrenforth et al., 2010; McNulty, 2013). A recent meta-analysis (Eastwick, Luchies, et al., 2013) found that the associations of participants' self-reported attractiveness and earning prospects (i.e., classic mate value assessment strategies) with their romantic partner's relationship evaluations were small ( $r=$ .07 and .08 , respectively), and consensus/objective measures of these two constructs (i.e., the assessment strategy highlighted in the current report) did not fare any better $(r=.08$ and .03 , respectively).

Most importantly, the core insight of the social relations model approach is that researchers must examine different relationships and/or group contexts to determine whether a behavior or quality is trait-like (Kenny \& Zaccaro, 1983), and no study to our knowledge has examined whether individual difference variables exhibit 
partner effects across more than one relationship. For example, does Dane's attachment anxiety negatively affect Betty's relationship satisfaction with him now as well as Felicia's relationship satisfaction with him 3 years later? Such partner effects could be extremely weak, as individual difference variables such as attachment anxiety and self-esteem frequently change in response to ongoing relationship experiences (Davila, Karney, \& Bradbury, 1999; Murray et al., 1996b). Also, the effect of these qualities on negative relational outcomes are mitigated in the wake of efforts to reframe how people experience and interpret relationship events (Marigold, Holmes, \& Ross, 2007) and by partners who make use of the appropriate conflict amelioration behaviors (Overall, Simpson, \& Struthers, 2013; Simpson \& Overall, in press). Until scholars conduct studies that assess data from individuals and their multiple romantic partners across time, we do not know the extent to which people are more or less loveable; the projected assessments of relationship quality used in the current report offer the best available approximation.

The current data also connect to the large literature on positive illusions in relationships: the tendency for individuals to view their romantic partner as more wonderful than the partner's selfassessment or a consensus-derived benchmark (Fletcher \& Kerr, 2010; Murray et al., 1996a, 1996b). Many studies have suggested that these positive illusions reflect participants' motivation to maintain their relationships in the face of difficulties. For example, participants' positive illusions are intensified when they encounter relationship threats (Rusbult, Van Lange, Wildschut, Yovetich, \& Verette, 2000), discover that their partner's virtues might actually be faults (Murray \& Holmes, 1993), or experience an implemental mindset (Gagné \& Lydon, 2001). The present data offer a complementary "cognitive" explanation for the existence of positive illusions. That is, positive illusions could emerge as a consequence of the naturally existing relationship variance in people's romantic evaluations of one another, variation that actually precedes the formation of the relationship. In other words, people exhibit positive illusions in relationships because two people are more likely to traverse the many steps between initial acquaintance and relationship formation if they happen to hold uniquely positive views of one another. Cognitive and motivational explanations frequently coexist (Kunda, 1990), and surely a substantial component of the romantic positive illusion is motivated. We merely suggest that the existence of a positive illusion may not entirely reflect the motivation to maintain the relationship, as it might even predate the formation of the relationship. Future studies that track romantic evaluations before and after a relationship has formed could bolster our understanding of these phenomena.

Finally, the present data also provide new insights into person perception processes. Affective measures (e.g., liking; Chapdelaine, Kenny, \& LaFontana, 1994; Malloy \& Albright, 1990) often produce variance partitioning results that differ from judgments of personality (Kenny, 1994). Romantic evaluations like those used in the present studies are highly affect-laden (Eastwick, Eagly, Finkel, \& Johnson, 2011), and it could be for this reason that we detected the first decreases in consensus over time. According to Kenny's (2004) PERSON model, participants achieve consensus in initial interactions largely because they rely on shared physical appearance stereotypes about the target. As participants observe more examples of the target's behaviors over time, consensus due to stereotypes is slowly replaced with consensus due to the target's underlying true qualities. Yet achieving consensus about a true underlying quality could be undermined by two elements of the relationship initiation process. The first is that participants must agree in their interpretation that the target's behaviors reflect the true quality, but the affective nature of romantic evaluations may lead participants to largely disagree about whether a particular behavior reflects a desirable or undesirable inner quality (e.g., Cassandra feels embarrassed when Dane sings karaoke in public, but Betty finds his self-assurance to be impressive). The second is that consensus should weaken if participants get to know one another in different settings (i.e., classrooms, parties, work, leisure activities) that elicit different behaviors. This asymmetric acquisition of knowledge surely applied to the Study 3 dyads and perhaps even applied to some of the Study 2 dyads at Time 2 (i.e., some dyads got to know each other better and in other contexts). Therefore, if people do in fact possess a core mate value intrinsic to the individual that inspires positive or negative romantic evaluations, it appears to be so weak that, as time passes, it drowns in the sea of idiosyncrasy that characterizes the highly affect-laden relationship initiation process.

\section{Strengths and Weaknesses}

This article sits at the intersection of three literatures: evolutionary perspectives on mate value (Back, Penke, Schmukle, \& Asendorpf, 2011), relationships research on the assessment of pair bond quality (Fletcher et al., 2000), and person perception studies of consensus versus uniqueness (Kenny, 2004). The current work contributes to the evolutionary literature by extending the study of mate value beyond self-assessments and initial interactions. In this way, the current studies help to bridge the gap between evolutionary perspectives on initial sexual appeal and evolutionary perspectives on the creation and maintenance of pair bonds (Eastwick, 2009). This work also contributes to the relationships literature by using a projected measure of relationship quality to quantify the unique effect of the relationship itself. The theoretical distinction between dyadic processes (e.g., interdependence dilemmas) and individual difference processes (e.g., attachment style dynamics) is a source of great tension in this literature (Finkel, 2010; Van Lange, 2010; Tran \& Simpson, 2009), yet most prior measurement strategies fail to cleanly separate the two. Furthermore, this work contributes to the person perception literature, as only a handful of studies (e.g., Asendorpf et al., 2011; Eastwick et al., 2007) have applied the social relations model to romantic contexts, and no prior social relations model studies have examined both initial and later romantic evaluations. Finally, Study 1 contained the first assessment of participants' own lay beliefs about mate value, and the two social relations model studies that we conducted had fairly large sample sizes, especially given the intensive design.

The current research also has weaknesses that could be addressed by future research. One strong feature of Study 2 is that participants had not chosen to interact with one another; rather, they happened to be assigned to the same class section (e.g., a closed field). However, these participants were all college students attending the same university, and it remains unknown how much perceiver, target, and relationship variance would emerge in a group with participants from very mixed backgrounds or social classes (cf. Li et al., 2013, Study 3). In addition, the present work did not track individuals as they formed romantic relationships 
with one another. Is it the case that two individuals who happen to hold uniquely positive views of each other are especially likely to form a romantic relationship? Some suggestive evidence comes from a modification of the classic classroom pairing game demonstration (Ellis \& Kelley, 1999): When participants played a version of the game that incorporated relationship variance, they became significantly less likely (relative to the original version of the game) to base their mating decisions on the partner's consensual level of desirability (Eastwick \& Buck, in press). Nevertheless, this is only a classroom demonstration, and future research should examine these possibilities among groups of individuals who exhibit a high base rate of actual relationship formation (e.g., dormitories).

Also, our results revealed a large amount of relationship variance in participants' romantic evaluations, but what features cause people to exhibit highly positive or negative relationship effects? Our results suggested that participants' actual similarity to one another was not a strong candidate (see also Tidwell et al., 2013), but in principle, any conceivable characteristic of the dyad could predict relationship variance. Contemporary research on human genetics offers an illustrative parallel (Turkheimer, 2000, 2011): For many decades, social science researchers have used quantitative genetics to document the large percentage of variance in humans' traits and behaviors that are due to genetic factors (e.g., $\sim 40 \%$ or higher; Petrill et al., 2004). Yet even with the completion of the Human Genome Project in 2003, the ability of physical sciences researchers to account for this variance using specific genetic markers has been extremely limited (e.g., $\sim 1 \%-3 \%$ ). This issue has been dubbed the "missing heritability problem" (Maher, 2008; Turkheimer, 2011), and it has spawned the search for new ways that genes might combine interactively to affect an organism's phenotype. Similarly, the massive amount of relationship variance exhibited by our participants suggests the following: If relationships scholars focus only on isolated, one-off predictors of romantic interest or relationship quality, we may actually underappreciate just how dyadic human relationships are. Variance partitioning reveals how much we do not yet know.

\section{Conclusion}

There is little doubt that some people have more objectively appealing qualities than others. Acquired through either good fortune or hard work, these qualities predict romantic success in initial attraction settings for those who possess them. Nevertheless, the current data hint at the possibility that human mating may depart substantially from a merit-based selection process. Romantically desirable traits actually appeared to be more relational than trait-like (i.e., consensual) across the contexts that we examined, and this difference between uniqueness and consensus was even more pronounced when people estimated how happy they would be with someone as a relationship partner. Among individuals who knew each other especially well, the data revealed very little consensus and large amounts of unique, relationship variance. These findings reflect the natural subjectivity inherent in our perceptions of others (Ross \& Nisbett, 1991). In some cases, this idiosyncrasy may generate frustration, especially if a desired other does not see the reality of one's outstanding qualities. Yet in other cases, this idiosyncrasy will prove fortuitous, as it permits nearly everyone a chance to form relationships where both partners view each other as uniquely desirable.

\section{References}

Afifi, W. A., \& Faulkner, S. L. (2000). On being "just friends": The frequency and impact of sexual activity in crosssex friendships. Journal of Social and Personal Relationships, 17, 205-222. doi:10.1177/ 0265407500172003

Altman, I., \& Taylor, D. A. (1973). Social penetration: The development of interpersonal relationships. New York, NY: Holt, Rinehart and Winston.

Apicella, C. L., \& Marlowe, F. W. (2007). Men's reproductive investment decisions: Mating, parenting, and self-perceived mate value. Human Nature, 18, 22-34. doi:10.1007/BF02820844

Asendorpf, J. B., Penke, L., \& Back, M. D. (2011). From dating to mating and relating: Predictors of initial and long-term outcomes of speeddating in a community sample. European Journal of Personality, 25, 16-30. doi:10.1002/per.768

Back, M. D., \& Kenny, D. A. (2010). The social relations model: How to understand dyadic processes. Social and Personality Psychology Compass, 4, 855-870. doi:10.1111/j.1751-9004.2010.00303.x

Back, M. D., Penke, L., Schmukle, S. C., \& Asendorpf, J. B. (2011). Knowing your own mate value: Sex-specific personality effects on the accuracy of expected mate choices. Psychological Science, 22, 984-989. doi:10.1177/0956797611414725

Back, M. D., Penke, L., Schmukle, S. C., Sachse, K., Borkenau, P., \& Asendorpf, J. B. (2011). Why mate choices are not as reciprocal as we assume: The role of personality, flirting and physical attractiveness. European Journal of Personality, 25, 120-132. doi:10.1002/per.806

Back, M. D., Schmukle, S. C., \& Egloff, B. (2011). A closer look at first sight: Social relations lens model analysis of personality and interpersonal attraction at zero acquaintance. European Journal of Personality, 25, 225-238. doi:10.1002/per.790

Baxter, L. A., \& Bullis, C. (1986). Turning points in developing romantic relationships. Human Communication Research, 12, 469-493. doi: 10.1111/j.1468-2958.1986.tb00088.x

Berscheid, E. (1985). Compatibility, interdependence, and emotion. In W Ickes (Ed.), Compatible and incompatible relationships (pp. 143-161). New York, NY: Springer. doi:10.1007/978-1-4612-5044-9_7

Berscheid, E., Dion, K., Walster, E., \& Walster, G. W. (1971). Physical attractiveness and dating choice: A test of the matching hypothesis. Journal of Experimental Social Psychology, 7, 173-189. doi:10.1016/ 0022-1031(71)90065-5

Berscheid, E., \& Reis, H. T. (1998). Attraction and close relationships. In D. T. Gilbert, S. T. Fiske, \& G. Lindzey (Eds.), The handbook of social psychology (4th ed., Vol. 2, pp. 193-281). New York, NY: McGrawHill.

Bisson, M. A., \& Levine, T. R. (2009). Negotiating a friends with benefits relationship. Archives of Sexual Behavior, 38, 66-73. doi:10.1007/ s10508-007-9211-2

Boyes, A. D., \& Fletcher, G. J. (2007). Metaperceptions of bias in intimate relationships. Journal of Personality and Social Psychology, 92, 286306. doi:10.1037/0022-3514.92.2.286

Bradbury, T. N., \& Karney, B. R. (2010). Intimate relationships. New York, NY: Norton.

Branje, S. J. T., van Aken, M. A. G., \& van Lieshout, C. F. M. (2002). Relational support in families with adolescents. Journal of Family Psychology, 16, 351-362. doi:10.1037/0893-3200.16.3.351

Brase, G. L., \& Guy, E. C. (2004). The demographics of mate value and self-esteem. Personality and Individual Differences, 36, 471-484. doi: 10.1016/S0191-8869(03)00117-X

Bullis, C., Clark, C., \& Sline, R. (1993). From passion to commitment: 
Turning points in romantic relationships. In P. J. Kalbfleisch (Ed.), Interpersonal communication: Evolving interpersonal relationships (pp. 213-236). Hillsdale, NJ: Erlbaum.

Buss, D. M., \& Barnes, M. (1986). Preferences in human mate selection. Journal of Personality and Social Psychology, 50, 559-570. doi: 10.1037/0022-3514.50.3.559

Cameron, C., Oskamp, S., \& Sparks, W. (1977). Courtship American style: Newspaper ads. Family Coordinator, 26, 27-30. doi:10.2307/581857

Campbell, L., Simpson, J. A., Boldry, J., \& Kashy, D. A. (2005). Perceptions of conflict and support in romantic relationships: The role of attachment anxiety. Journal of Personality and Social Psychology, 88, 510-531. doi:10.1037/0022-3514.88.3.510

Campbell, L., Simpson, J., Kashy, D., \& Fletcher, G. (2001). Ideal standards, the self, and flexibility of ideals in close relationships. Personality and Social Psychology Bulletin, 27, 447-462. doi:10.1177/ 0146167201274006

Campbell, L., \& Wilbur, C. J. (2009). Are the traits we prefer in potential mates the traits they value in themselves? An analysis of sex differences in the self-concept. Self and Identity, 8, 418-446. doi:10.1080/ 15298860802505434

Chapdelaine, A., Kenny, D. A., \& LaFontana, K. M. (1994). Matchmaker, matchmaker, can you make me a match? Predicting liking between two unacquainted persons. Journal of Personality and Social Psychology, 67, 83-91. doi:10.1037/0022-3514.67.1.83

Christensen, H. T. (1947). Student views on mate selection. Marriage and Family Living, 9, 85-88. doi:10.2307/347505

Conley, T. D., Ziegler, A., Moors, A. C., Matsick, J. L., \& Valentine, B. (2013). A critical examination of popular assumptions about the benefits and outcomes of monogamous relationships. Personality and Social Psychology Review, 17, 124-141. doi:10.1177/1088868312467087

Davila, J., Karney, B. R., \& Bradbury, T. N. (1999). Attachment change processes in the early years of marriage. Journal of Personality and Social Psychology, 76, 783-802. doi:10.1037/0022-3514.76.5.783

Donnellan, M. B., Conger, R. D., \& Bryant, C. M. (2004). The Big Five and enduring marriages. Journal of Research in Personality, 38, 481504. doi:10.1016/j.jrp.2004.01.001

Dyrenforth, P. S., Kashy, D. A., Donnellan, M. B., \& Lucas, R. E. (2010). Predicting relationship and life satisfaction from personality in nationally representative samples from three countries: The relative importance of actor, partner, and similarity effects. Journal of Personality and Social Psychology, 99, 690-702. doi:10.1037/a0020385

Eastwick, P. W. (2009). Beyond the Pleistocene: Using phylogeny and constraint to inform the evolutionary psychology of human mating. Psychological Bulletin, 135, 794-821. doi:10.1037/a0016845

Eastwick, P. W. (2013). Cultural influences on attraction. In J. A. Simpson \& L. Campbell (Eds.), The Oxford handbook of close relationships (pp. 161-182). New York, NY: Oxford University Press.

Eastwick, P. W., \& Buck, A. A. (in press). Too much matching: A social relations model enhancement of the pairing game. Teaching of Psychology.

Eastwick, P. W., Eagly, A. H., Finkel, E. J., \& Johnson, S. E. (2011). Implicit and explicit preferences for physical attractiveness in a romantic partner: A double dissociation in predictive validity. Journal of Personality and Social Psychology, 101, 993-1011. doi:10.1037/a0024061

Eastwick, P. W., \& Finkel, E. J. (2007). [Northwestern speed-dating study II]. Unpublished raw data.

Eastwick, P. W., \& Finkel, E. J. (2008). Sex differences in mate preferences revisited: Do people know what they initially desire in a romantic partner? Journal of Personality and Social Psychology, 94, 245-264. doi:10.1037/0022-3514.94.2.245

Eastwick, P. W., Finkel, E. J., Mochon, D., \& Ariely, D. (2007). Selective versus unselective romantic desire: Not all reciprocity is created equal. Psychological Science, 18, 317-319. doi:10.1111/j.1467-9280.2007 .01897.x
Eastwick, P. W., Luchies, L. B., Finkel, E. J., \& Hunt, L. L. (2013). The predictive validity of ideal partner preferences: A review and metaanalysis. Psychological Bulletin. Advance online publication. doi: 10.1037/a0032432

Eastwick, P. W., Morgan, T. A., Graham, L. T., Slotter, E. B., Luchies, L. B., \& Neff, L. A. (2013). Integrating strategy and stage perspectives on mating: Male physical attractiveness as a test case. Unpublished manuscript, University of Texas at Austin.

Ellis, B. J., \& Kelley, H. H. (1999). The pairing game: A classroom demonstration of the matching phenomenon. Teaching of Psychology, 26, 118-121. doi:10.1207/s15328023top2602_8

Ellis, B. J., Simpson, J. A., \& Campbell, L. (2002). Trait-specific dependence in romantic relationships. Journal of Personality, 70, 611-659. doi:10.1111/1467-6494.05019

Fabrigar, L. R., Wegener, D. T., MacCallum, R. C., \& Strahan, E. J. (1999). Evaluating the use of exploratory factor analysis in psychological research. Psychological Methods, 4, 272-299. doi:10.1037/1082989X.4.3.272

Figueredo, A. J., Sefcek, J. A., \& Jones, D. N. (2006). The ideal romantic partner personality. Personality and Individual Differences, 41, 431441. doi:10.1016/j.paid.2006.02.004

Finkel, E. J. (2010). In the pursuit of science. Personal Relationships, 17, 158-160. doi:10.1111/j.1475-6811.2010.01263.x

Finkel, E. J., Eastwick, P. W., Karney, B. R., Reis, H. T., \& Sprecher, S. (2012). Online dating: A critical analysis from the perspective of psychological science. Psychological Science in the Public Interest, 13, 3-66. doi:10.1177/1529100612436522

Fisher, M., Cox, A., Bennett, S., \& Gavric, D. (2008). Components of self-perceived mate value. Journal of Social, Evolutionary, and Cultural Psychology, 2, 156-168.

Fletcher, G. J. O., \& Kerr, P. S. G. (2010). Through the eyes of love: Reality and illusion in intimate relationships. Psychological Bulletin 136, 627-658. doi:10.1037/a0019792

Fletcher, G. J. O., \& Simpson, J. A. (2000). Ideal standards in close relationships: Their structure and functions. Current Directions in Psychological Science, 9, 102-105. doi:10.1111/1467-8721.00070

Fletcher, G. J. O., Simpson, J. A., Campbell, L., \& Overall, N. C. (2013) The science of intimate relationships. Malden, MA: Wiley-Blackwell.

Fletcher, G. J. O., Simpson, J. A., \& Thomas, G. (2000). The measurement of perceived relationship quality components: A confirmatory factor analytic approach. Personality and Social Psychology Bulletin, 26, 340 354. doi: $10.1177 / 0146167200265007$

Fletcher, G. J. O., Simpson, J. A., Thomas, G., \& Giles, L. (1999). Ideals in intimate relationships. Journal of Personality and Social Psychology, 76, 72-89. doi:10.1037/0022-3514.76.1.72

Fletcher, G. J. O., Tither, J. M., O'Loughlin, C., Friesen, M., \& Overall, N. (2004). Warm and homely or cold and beautiful? Sex differences in trading off traits in mate selection. Personality and Social Psychology Bulletin, 30, 659-672. doi:10.1177/0146167203262847

Fraley, R. C., \& Shaver, P. R. (2000). Adult romantic attachment: Theoretical developments, emerging controversies, and unanswered questions. Review of General Psychology, 4, 132-154. doi:10.1037/10892680.4.2.132

Funder, D. C., \& Colvin, C. R. (1988). Friends and strangers: Acquaintanceship, agreement, and the accuracy of personality judgment. Journal of Personality and Social Psychology, 55, 149-158. doi:10.1037/00223514.55.1.149

Gagné, F. M., \& Lydon, J. E. (2001). Mind-set and close relationships: When bias leads to (in)accurate predictions. Journal of Personality and Social Psychology, 81, 85-96. doi:10.1037/0022-3514.81.1.85

Geary, D. C. (2000). Evolution and proximate expression of human paternal investment. Psychological Bulletin, 126, 55-77. doi:10.1037/00332909.126.1.55 
Giblin, F., \& Lakey, B. (2010). Integrating mentoring and social support research within the context of stressful medical training. Journal of Social and Clinical Psychology, 29, 771-796. doi:10.1521/jscp.2010.29 .7 .771

Glenn, N. D. (2002). A plea for greater concern about the quality of marital matching. In A. J. Hawkins, L. D. Wardle, \& D. O. Coolidge (Eds.), Revitalizing the institution of marriage for the twenty-first century: An agenda for strengthening marriage (pp. 45-58). Westport, CT: Praeger.

Griffin, D. W., Murray, S. L., \& Gonzalez, R. (1999). Difference score correlations in relationship research: A conceptual primer. Personal Relationships, 6, 505-518. doi:10.1111/j.1475-6811.1999.tb00206.x

Gutierres, S. E., Kenrick, D. T., \& Partch, J. J. (1999). Beauty, dominance, and the mating game: Contrast effects in self-assessment reflect gender differences in mate selection. Personality and Social Psychology Bulletin, 25, 1126-1134. doi:10.1177/01461672992512006

Hazan, C., \& Diamond, L. M. (2000). The place of attachment in human mating. Review of General Psychology, 4, 186-204. doi:10.1037/10892680.4.2.186

Hazan, C., \& Shaver, P. R. (1994). Attachment as an organizational framework for research on close relationships. Psychological Inquiry, 5, 1-22. doi:10.1207/s15327965pli0501_1

Hewlett, B. S. (2000). Culture, history, and sex: Anthropological contributions to conceptualizing father involvement. Marriage \& Family Review, 29, 59-73. doi:10.1300/J002v29n02_05

Hill, R. (1945). Campus values in mate-selection. Journal of Home Economics, 37, 554-558.

Hurtado, A. M., \& Hill, K. R. (1992). Paternal effect on offspring survivorship among Ache and Hiwi hunter-gatherers: Implications for modeling pair-bond stability. In B. S. Hewlett (Ed.), Father-child relations: Cultural and biosocial contexts (pp. 31-55). New York, NY: Aldine de Gruyter.

Huston, T. L., Surra, C. A., Fitzgerald, N. M., \& Cate, R. M. (1981). From courtship to marriage: Mate selection as an interpersonal process. Personal Relationships, 2, 53-88.

Ickes, W. (Ed.). (1985). Compatible and incompatible relationships. New York, NY: Springer. doi:10.1007/978-1-4612-5044-9

Ingham, R., Woodcock, A., \& Stenner, K. (1991). Getting to know you ... Young people's knowledge of their partners at first intercourse. Journal of Community \& Applied Social Psychology, 1, 117-132. doi:10.1002/ casp. 2450010206

Kaestle, C. E., \& Halpern, C. T. (2005). Sexual activity among adolescents in romantic relationships with friends, acquaintances, or strangers. Archives of Pediatrics \& Adolescent Medicine, 159, 849-853. doi: 10.1001/archpedi.159.9.849

Kalick, S. M., \& Hamilton, T. E. (1986). The matching hypothesis reexamined. Journal of Personality and Social Psychology, 51, 673-682. doi:10.1037/0022-3514.51.4.673

Kaplan, H. S., Lancaster, J. B., Johnson, S. E., \& Bock, J. A. (1995). Does observed fertility maximize fitness among New Mexican men? Human Nature, 6, 325-360. doi:10.1007/BF02734205

Katz, M. M., \& Konner, M. J. (1981). The role of the father: An anthropological perspective. In M. E. Lamb (Ed.), The role of the father in child development (Vol. 2, pp. 155-185). New York, NY: Wiley.

Kavanagh, P. S., Robins, S. C., \& Ellis, B. J. (2010). The mating sociometer: A regulatory mechanism for mating aspirations. Journal of Personality and Social Psychology, 99, 120-132. doi:10.1037/a0018188

Kenny, D. A. (1994). Interpersonal perception: A social relations analysis. New York, NY: Guilford Press.

Kenny, D. A. (2004). PERSON: A general model of interpersonal perception. Personality and Social Psychology Review, 8, 265-280. doi: 10.1207/s15327957pspr0803_3

Kenny, D. A. (2010). Metaperception of affect: Do we know who likes us? Paper presented at the University of Massachusetts at Amherst.
Kenny, D. A., Albright, L., Malloy, T. E., \& Kashy, D. A. (1994) Consensus in interpersonal perception: Acquaintance and the Big Five Psychological Bulletin, 116, 245-258. doi:10.1037/0033-2909.116.2 .245

Kenny, D. A., Kashy, D. A., \& Cook, W. L. (2006). Dyadic data analysis. New York, NY: Guilford Press.

Kenny, D. A., \& La Voie, L. (1984). The social relations model. In L. Berkowitz (Ed.), Advances in experimental social psychology (Vol. 18 pp. 141-182). New York, NY: Academic Press.

Kenny, D. A., \& Zaccaro, S. J. (1983). An estimate of variance due to traits in leadership. Journal of Applied Psychology, 68, 678-685. doi: 10.1037/0021-9010.68.4.678

Kenrick, D. T., Groth, G. E., Trost, M. R., \& Sadalla, E. K. (1993). Integrating evolutionary and social exchange perspectives on relationships: Effects of gender, self-appraisal, and involvement level on mate selection criteria. Journal of Personality and Social Psychology, 64, 951-969. doi:10.1037/0022-3514.64.6.951

Kirkpatrick, L. A., \& Ellis, B. J. (2001). An evolutionary-psychological approach to self-esteem: Multiple domains and multiple functions. In G. J. O. Fletcher \& M. S. Clark (Eds.), Blackwell handbook of social psychology: Interpersonal processes (pp. 411-436). Malden, MA: Blackwell.

Kirsner, B. R., Figueredo, A. J., \& Jacobs, W. J. (2003). Self, friends, and lovers: Structural relations among beck depression inventory scores and perceived mate values. Journal of Affective Disorders, 75, 131-148. doi:10.1016/S0165-0327(02)00048-4

Knapp, M. L. (1984). Interpersonal communication and human relationships. Boston, MA: Allyn \& Bacon.

Kunda, Z. (1990). The case for motivated reasoning. Psychological Bulletin, 108, 480-498. doi:10.1037/0033-2909.108.3.480

Kurzban, R., \& Leary, M. R. (2001). Evolutionary origins of stigmatization: The functions of social exclusion. Psychological Bulletin, 127, 187-208. doi:10.1037/0033-2909.127.2.187

Kwang, T., \& Swann, W. B. (2010). Do people embrace praise even when they feel unworthy? A review of critical tests of self-enhancement versus self-verification. Personality and Social Psychology Review, 14, 263 280. doi: $10.1177 / 1088868310365876$

Lakey, B., McCabe, K. M., Fisicaro, S. A., \& Drew, J. B. (1996). Environmental and personal determinants of support perceptions: Three generalizability studies. Journal of Personality and Social Psychology, 70, 1270-1280. doi:10.1037/0022-3514.70.6.1270

Landolt, M. A., Lalumière, M. L., \& Quinsey, V. L. (1995). Sex differences in intra-sex variations in human mating tactics: An evolutionary approach. Ethology and Sociobiology, 16, 3-23. doi:10.1016/01623095(94)00012-V

Lewin, K. (1935). A dynamic theory of personality (D. K. Adams \& K. E. Zener, Trans.). New York, NY: McGraw-Hill.

Lewin, K. (1936). Principles of topological psychology (F. Heider \& G. M Heider, Trans.). New York, NY: McGraw-Hill. doi:10.1037/10019-000

Li, N. P., Yong, J. C., Tov, W., Sng, O., Fletcher, G. J. O., Valentine, K. A., ... Balliet, D. (2013). Mate preferences do predict attraction and choices in the early stages of mate selection. Journal of Personality and Social Psychology, 105, 757-776. doi:10.1037/a0033777

Maher, B. (2008). The case of the missing heritability. Nature, 456, 18-21. doi:10.1038/456018a

Malloy, T. E., \& Albright, L. (1990). Interpersonal perception in a social context. Journal of Personality and Social Psychology, 58, 419-428. doi:10.1037/0022-3514.58.3.419

Manning, W. D., Giordano, P. C., \& Longmore, M. A. (2006). Hooking up: The relationship contexts of "nonrelationship" sex. Journal of Adolescent Research, 21, 459-483. doi:10.1177/0743558406291692

Marcus, D. K., Kashy, D. A., \& Baldwin, S. A. (2009). Studying psychotherapy using the one-with-many design: The therapeutic alliance as an 
exemplar. Journal of Counseling Psychology, 56, 537-548. doi:10.1037/ a0017291

Marcus, D. K., \& Miller, R. S. (2003). Sex differences in judgments of physical attractiveness: A social relations analysis. Personality and Social Psychology Bulletin, 29, 325-335. doi:10.1177/0146167202250193

Marigold, D. C., Holmes, J. G., \& Ross, M. (2007). More than words: Reframing compliments from romantic partners fosters security in low self-esteem individuals. Journal of Personality and Social Psychology, 92, 232-248. doi:10.1037/0022-3514.92.2.232

McNulty, J. K. (2013). Personality and relationships. In J. A. Simpson \& L. Campbell (Eds.), The Oxford handbook of close relationships (pp. 535-552). New York, NY: Oxford University Press.

Miller, L. C., \& Fishkin, S. A. (1997). On the dynamics of human bonding and reproductive success: Seeking windows on the adapted-for-humanenvironmental interface. In J. A. Simpson \& D. T. Kenrick (Eds.), Evolutionary social psychology (pp. 197-236). Mahwah, NJ: Erlbaum.

Miller, L. C., Pedersen, W. C., \& Putcha-Bhagavatula, A. (2005). Promiscuity in an evolved pair-bonding system: Mating within and outside the Pleistocene box. Behavioral and Brain Sciences, 28, 290-291. doi: $10.1017 / \mathrm{S} 0140525 \mathrm{X} 05370051$

Miller, R. S. (2012). Intimate relationships (6th ed.). New York, NY: McGraw-Hill.

Murray, S. L., Bellavia, G. M., Rose, P., \& Griffin, D. W. (2003). Once hurt, twice hurtful: How perceived regard regulates daily marital interactions. Journal of Personality and Social Psychology, 84, 126-147. doi:10.1037/0022-3514.84.1.126

Murray, S. L., \& Holmes, J. G. (1993). Seeing virtues in faults: Negativity and the transformation of interpersonal narratives in close relationships. Journal of Personality and Social Psychology, 65, 707-722. doi: 10.1037/0022-3514.65.4.707

Murray, S. L., \& Holmes, J. G. (2009). The architecture of interdependent minds: A motivation-management theory of mutual responsiveness. Psychological Review, 116, 908-928. doi:10.1037/a0017015

Murray, S. L., Holmes, J. G., \& Griffin, D. W. (1996a). The benefits of positive illusions: Idealization and the construction of satisfaction in close relationships. Journal of Personality and Social Psychology, 70, 79-98. doi:10.1037/0022-3514.70.1.79

Murray, S. L., Holmes, J. G., \& Griffin, D. W. (1996b). The self-fulfilling nature of positive illusions in romantic relationships: Love is not blind, but prescient. Journal of Personality and Social Psychology, 71, 11551180. doi:10.1037/0022-3514.71.6.1155

Murray, S. L., Holmes, J. G., \& Griffin, D. W. (2000). Self-esteem and the quest for felt security: How perceived regard regulates attachment processes. Journal of Personality and Social Psychology, 78, 478-498. doi:10.1037/0022-3514.78.3.478

Nielsen, M., \& Tomaselli, K. (2010). Overimitation in Kalahari Bushman children and the origins of human cultural cognition. Psychological Science, 21, 729-736. doi:10.1177/0956797610368808

Olkin, I., \& Finn, J. D. (1995). Correlations redux. Psychological Bulletin, 118, 155-164. doi:10.1037/0033-2909.118.1.155

Overall, N. C., Fletcher, G. J. O., \& Simpson, J. A. (2006). Regulation processes in intimate relationships: The role of ideal standards. Journal of Personality and Social Psychology, 91, 662-685. doi:10.1037/00223514.91.4.662

Overall, N. C., Simpson, J. A., \& Struthers, H. (2013). Buffering attachment-related avoidance: Softening emotional and behavioral defenses during conflict discussions. Journal of Personality and Social Psychology, 104, 854-871. doi:10.1037/a0031798

Park, B., Kraus, S., \& Ryan, C. S. (1997). Longitudinal changes in consensus as a function of acquaintance and agreement in liking. Journal of Personality and Social Psychology, 72, 604-616. doi:10.1037/00223514.72.3.604

Penke, L., \& Denissen, J. J. (2008). Sex differences and lifestyle-dependent shifts in the attunement of self-esteem to self-perceived mate value:
Hints to an adaptive mechanism? Journal of Research in Personality, 42, 1123-1129. doi:10.1016/j.jrp.2008.02.003

Penke, L., Todd, P. M., Lenton, A. P., \& Fasolo, B. (2007). How selfassessments can guide human mating decisions. In G. Geher \& G. F. Miller (Eds.), Mating intelligence: New insights into intimate relationships, human sexuality, and the mind's reproductive system (pp. 37-75). Mahwah, NJ: Erlbaum.

Petrill, S. A., Lipton, P. A., Hewitt, J. K., Plomin, R., Cherny, S. S., Corley, R., \& DeFries, J. C. (2004). Genetic and environmental contributions to general cognitive ability through the first 16 years of life. Developmental Psychology, 40, 805-812. doi:10.1037/0012-1649.40.5.805

Regan, P. C. (1998a). Minimum mate selection standards as a function of perceived mate value, relationship context, and gender. Journal of Psychology \& Human Sexuality, 10, 53-73. doi:10.1300/ J056v10n01_04

Regan, P. C. (1998b). What if you can't get what you want? Willingness to compromise ideal mate selection standards as a function of sex, mate value, and relationship context. Personality and Social Psychology Bulletin, 24, 1294-1303. doi:10.1177/01461672982412004

Ross, L. (1987). The problem of construal in social inference and social psychology. In N. E. Grunberg, R. E. Nisbett, J. Rodin, \& J. E. Singer (Eds.), A distinctive approach to psychological research: The influence of Stanley Schachter (pp. 118-150). Hillsdale, NJ: Erlbaum.

Ross, L., \& Nisbett, R. E. (1991). The person and the situation: Perspectives of social psychology. New York, NY: McGraw-Hill.

Rusbult, C. E., Van Lange, P. A., Wildschut, T., Yovetich, N. A., \& Verette, J. (2000). Perceived superiority in close relationships: Why it exists and persists. Journal of Personality and Social Psychology, 79, 521-545. doi:10.1037/0022-3514.79.4.521

Rusbult, C. E., Martz, J. M., \& Agnew, C. R. (1998). The investment model scale: Measuring commitment level, satisfaction level, quality of alternatives, and investment size. Personal Relationships, 5, 357-391. doi:10.1111/j.1475-6811.1998.tb00177.x

Simpson, J. A., Fletcher, G. J. O., \& Campbell, L. (2001). The structure and function of ideal standards in close relationships. In G. J. O. Fletcher \& M. S. Clark (Eds.), Blackwell handbook of social psychology: Interpersonal processes (pp. 86-106). Malden, MA: Blackwell.

Simpson, J. A., \& Overall, N. C. (in press). Partner buffering of attachment insecurity. Current Directions in Psychological Science.

Sprecher, S. L. (2011). Relationship compatibility, compatible matches, and compatibility matching. Acta de Investigación Psicológica, 1, $187-215$.

Stewart-Williams, S., \& Thomas, A. (2013). The ape that thought it was a peacock: Does evolutionary psychology exaggerate human sex differences? Psychological Inquiry, 24, 137-168. doi:10.1080/1047840X.2013.804899

Symons, D. (1987). Can Darwin's view of life shed light on human sexuality? In J. H. Geer \& W. T. O'Donohue (Eds.), Theories of human sexuality (pp. 91-125). New York, NY: Plenum Press.

Taylor, L. S., Fiore, A. T., Mendelsohn, G., \& Cheshire, C. (2011). "Out of my league": A real-world test of the matching hypothesis. Personality and Social Psychology Bulletin, 37, 942-954. doi:10 .1177/0146167211409947

Tidwell, N. D., Eastwick, P. W., \& Finkel, E. J. (2013). Perceived, not actual, similarity predicts initial attraction in a live romantic context: Evidence from the speed-dating paradigm. Personal Relationships, 20, 199-215. doi:10.1111/j.1475-6811.2012.01405.x

Todd, P. M., \& Miller, G. F. (1999). From pride and prejudice to persuasion: Satisficing in mate search. In G. Gigerenzer \& P. M. Todd (Eds.), Simple heuristics that make us smart: Evolution and cognition (pp. 287-308). New York, NY: Oxford University Press.

Todd, P. M., Penke, L., Fasolo, B., \& Lenton, A. P. (2007). Different cognitive processes underlie human mate choices and mate preferences. Proceedings of the National Academy of Sciences of the United States of America, 104, 15011-15016. doi:10.1073/pnas.0705290104 
Traeen, B., Lewin, B., \& Sundet, J. M. (1992). The real and the ideal; gender differences in heterosexual behaviour among Norwegian adolescents. Journal of Community \& Applied Social Psychology, 2, 227-237. doi:10.1002/casp. 2450020402

Tran, S., \& Simpson, J. A. (2009). Prorelationship maintenance behaviors: The joint roles of attachment and commitment. Journal of Personality and Social Psychology, 97, 685-698. doi:10.1037/a0016418

Turkheimer, E. (2000). Three laws of behavior genetics and what they mean. Current Directions in Psychological Science, 9, 160-164. doi: 10.1111/1467-8721.00084

Turkheimer, E. (2011). Still missing. Research in Human Development, 8 , 227-241. doi:10.1080/15427609.2011.625321

Van Lange, P. A. M. (2010). It is the relationship, stupid. Personal Relationships, 17, 176-179. doi:10.1111/j.1475-6811.2010.01270.x

Vazire, S. (2006). Informant reports: A cheap, fast, and easy method for personality assessment. Journal of Research in Personality, 40, 472481. doi:10.1016/j.jrp.2005.03.003

Waynforth, D. (2001). Mate choice trade-offs and women's preference for physically attractive men. Human Nature, 12, 207-219. doi:10.1007/s12110001-1007-9

Wilbur, C. J., \& Campbell, L. (2011). Humor in romantic contexts: Do men participate and women evaluate? Personality and Social Psychology Bulletin, 37, 918-929. doi:10.1177/0146167211405343

Winking, J. (2006). Are men really that bad as fathers? The role of men's investments. Biodemography and Social Biology, 53, 100-115. doi: 10.1080/19485565.2006.9989119

Woodruffe, C. (1984). The consistency of presented personality: Additional evidence from aggregation. Journal of Personality, 52, 307-317. doi:10.1111/j.1467-6494.1984.tb00353.x

Zeifman, D., \& Hazan, C. (2008). Pair bonds as attachments: Reevaluating the evidence. In J. Cassidy \& P. R. Shaver (Eds.), The handbook of attachment: Theory, research, and clinical applications (2nd ed., pp. 436-455). New York, NY: Guilford Press.

Zou, G. Y. (2007). Toward using confidence intervals to compare correlations. Psychological Methods, 12, 399-413. doi:10.1037/1082-989X .12.4.399

\section{Appendix A}

\section{Mate Value Essay Examples, Study 1}

Example 1: A valuable mate would be healthy, in shape, and emotionally stable. High moral standards and an easygoing personality with a sense of humor. Someone who would be responsible and could raise kids. Besides being physically attractive, she must have good genes that could pass to our kids. A healthy and optimistic lifestyle. Someone who likes to have fun and keeps up with work. A valuable mate will have character and a sense of what is right and wrong. Not two-faced and open-minded, but a similar view as I have on worldly issues. She must be intelligent and diligent.

Example 2: I really feel like someone of "mate value" would be someone who helps me become the best person I can be, the best version of myself. I would like someone supportive and open that
I could talk to and trust. I feel like loyalty and dependability are really important. I think that if I were to describe myself as a valuable mate it would mean that I was willing to do these same things, to be supportive and able to be confided in. I also feel like mate should equal children, so I would want to mate with someone who I thought would be a good father figure for my children. That would be someone who values family time and family values. Also, I think it would be important for us to view the world in the same way. I would want someone who shares my views about life and faith, things that are very important to me. I also feel like I would want someone committed. I would hold myself to these standards as well.

(Appendices continue) 


\section{Appendix B}

\section{SAS Variance Partitioning Code, Study 2}

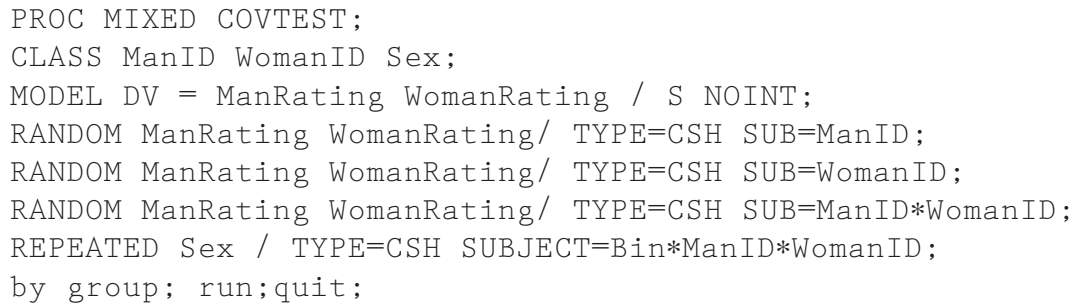

In addition to the mate value variables of interest, the social relations model design necessitated the creation of six other variables. Two variables served as participant labels: ManID served as a unique identifier for the man, and WomanID served as a unique identifier for the woman. To denote which person provided the ratings in each record, two dummy variables were also created: ManRating for the ratings provided by the man and WomanRating for ratings provided by the woman. The variable Sex was a categorical variable that denoted which participant was doing the rating (man or woman). Finally, Bin was a dummy variable that indicated which of the two bins appeared on that row of the data set.

Example for vitality/attractiveness (men, Group 1, Time 1, bins Version 1) with SAS output labels:

$$
\begin{aligned}
& \text { Perceiver variance }=\operatorname{Var}(1) \text { ManID }=.2362 \\
& \text { Target variance }=\operatorname{Var}(1) \text { WomanID }=.1328 \\
& \text { Relationship variance }=\operatorname{Var}(1) \text { ManID } * \text { WomanID }=.5636 \\
& \text { Error variance }=\operatorname{Var}(1) \operatorname{Bin} * \text { ManID } * \text { WomanID }=.3030
\end{aligned}
$$

Perceiver variance percentage $=.2362 \div(.2362+.1328+.5636+.3030)=\mathbf{1 9 . 1 \%}$

Target variance percentage $=.1328 \div(.2362+.1328+.5636+.3030)=\mathbf{1 0 . 7 \%}$

Relationship variance percentage $=.5636 \div(.2362+.1328+.5636+.3030)=\mathbf{4 5 . 6 \%}$

In the actual SAS output, the four additional parameters labeled $\operatorname{Var}(2)$ are the women's estimates. The results that appear in Table 4 are the average of the percentages calculated for men and women for bins Versions 1 and 2 (see footnote 3 ) for all groups.

\section{Appendix C}

\section{SAS Variance Partitioning Code, Study 3}

PROC MIXED CL COVTEST ASYCOV;

CLASS FPCode TargCode Role Measure;

MODEL DV = FPRating*Bin1 TargRating*Bin1 FPRating*Bin2 TargRating*Bin2 /

NOINT S DDFM=SATTERTH;

RANDOM FPRating TargRating / gcorr sub=FPCode TYPE=un;

RANDOM FPRating TargRating/gcorr sub=FPCode*TargCode type=un;

REPEATED Role / sub=Measure*FPCode*TargCode TYPE=un;

run; quit;

FPCode served as a unique identifier for the focal person, and TargCode served as a unique identifier for the informant. FPRating was a dummy variable indicating ratings provided by the focal person, and TargRating was a dummy variable indicating ratings provided by the informant. The variable Role was a categorical variable that denoted which participant was doing the rating (focal person or informant). Bin 1 and Bin 2 were two dummy variables that indicated which of the two bins was on that row of the data set; Measure was a categorical variable identical to Bin1. 
Example for vitality/attractiveness (bins Version 1) with SAS output parameters:

Ratings provided by focal persons:

$$
\begin{aligned}
& \text { Perceiver variance }=\mathrm{UN}(1,1) \text { FPCode }=.5038 \\
& \text { Relationship }+ \text { target variance }=\mathrm{UN}(1,1) \text { FPCode } * \text { TargCode }=1.0355 \\
& \text { Error variance }=\mathrm{UN}(1,1) \text { Measure } * \text { FPCode } * \text { TargCode }=.3626
\end{aligned}
$$

Ratings provided by informants:

$$
\begin{aligned}
& \text { Target variance }=\mathrm{UN}(2,2) \text { FPCode }=.0840 \\
& \text { Relationship }+ \text { perceiver variance }=\mathrm{UN}(2,2) \text { FPCode } * \text { TargCode }=1.0393 \\
& \text { Error variance }=\mathrm{UN}(2,2) \text { Measure } * \text { FPCode } * \text { TargCode }=.1869 \\
& \text { Perceiver variance percentage }=.5038 \div(.5038+1.0355+.3626)=\mathbf{2 6 . 5 \%} \\
& \text { Target variance percentage }=.0840 \div(.0840+1.0393+.1869)=\mathbf{6 . 4 \%}
\end{aligned}
$$

Relationship variance percentage for Focal Persons:

$$
\begin{aligned}
& \text { Step 1: } 1.0355 \div(.5038+1.0355+.3626)=54.4 \% \\
& \text { Step 2: } 54.4 \%-6.4 \%=48.0 \%(\text { i.e., “clean" estimate) }
\end{aligned}
$$

Relationship variance percentage for informants:

$$
\begin{gathered}
\text { Step 1: } 1.0393 \div(.0840+1.0393+.1869)=79.3 \% \\
\text { Step 2: } 79.3 \%-26.5 \%=52.8 \%(\text { i.e., "clean" estimate }) \\
\text { Relationship variance percentage average }=(48.0 \%+52.8 \%) \div 2=\mathbf{5 0 . 4 \%} .
\end{gathered}
$$

The results that appear in Table 8 are the average of the percentages calculated for bins Versions 1 and 2 (see footnote 3).

\section{Appendix D}

\section{Hypothesis Testing Procedures, Study 3}

The test comparing target with relationship variance is a $z$ test; the numerator is the difference between the raw relationship and target variance estimates, and the denominator is the pooled standard error of the relationship and target variance estimates calculated using the following equation (D. A. Kenny, personal communication, March 21, 2013; Olkin \& Finn, 1995; Zou, 2007):

$$
\mathrm{SE}_{\text {Pooled }}=V\left(\mathrm{SE}_{\mathrm{Rel}}^{2}+\mathrm{SE}_{\mathrm{Par}}^{2}-2 * \mathrm{COV}_{\mathrm{Rel}-\mathrm{Par}}\right) .
$$

$\mathrm{SE}_{\mathrm{Rel}}$ is the standard error for the relationship variance estimate, $\mathrm{SE}_{\mathrm{Par}}$ is the standard error for the target variance estimate, and $\mathrm{COV}_{\text {Rel-Par }}$ is the covariance between $\mathrm{SE}_{\mathrm{Rel}}$ and $\mathrm{SE}_{\mathrm{Par}}$ (provided by the SAS ASYCOV command). Relationship variance estimates were "cleaned" by subtracting the perceiver variance estimate from the informant relationship variance estimate and subtracting the target variance estimate from the focal person relationship variance estimate. Hypothesis tests were conducted using the av- erage of the two relationship variance estimates/standard errors produced by focal persons and targets.

To calculate the Construct Type $\times$ Variance Type interaction term, the numerator of the $z$ test was the interaction contrast among the average estimates for the four cells, and the denominator was the pooled standard error for the four cells. This denominator does not account for $\mathrm{COV}_{\text {Rel-Par, }}$ as the SAS code cannot calculate the covariances between classic and relational construct target variances and relationship variances. However, omitting $\mathrm{COV}_{\text {Rel-Par }}$ produces a conservative hypothesis test (i.e., a larger denominator in the $z$ test), as these particular covariances are surely positive given that the constructs themselves correlate highly (i.e., $r=\sim .60$ ).

Received May 30, 2013 Revision received January 9, 2014 Accepted January 10, 2014 